\title{
Fuel Taxation, Emissions Policy, and Competitive Advantage in the Diffusion of European Diesel Automobiles *
}

\author{
Eugenio J. Miravete ${ }^{\dagger} \quad$ María J. Moral ${ }^{\ddagger} \quad$ Jeff Thurk ${ }^{\S}$
}

January 2018

\begin{abstract}
Import tariffs have decreased significantly over the past 30 years due to a large number of economic integration agreements. We investigate whether national policies can be an effective replacement for tariffs to protect domestic industry. Our focus is the European automobile market where we show fuel taxes and vehicle emissions policy favored diesel vehicles, a technology popular with European consumers but largely offered only by domestic automakers. We estimate a discrete choice, oligopoly model of horizontally differentiated products using Spanish automobile registration data where we observe engine type. We show European automakers benefited from pro-diesel fuel taxes and a lenient $N O_{x}$ emissions policy to earn significant profits from diesel cars. Had regulators used policies which did not favor diesels, consumers would have shifted consumption towards gasoline-powered imports. We show both policies amounted to significant non-tariff trade policies equivalent to an import tariff between two to three times the official rate.
\end{abstract}

Keywords: Trade Policy, Import Tariff Equivalence, Diesel Automobiles, Emission Standards, Fuel Taxation.

JEL Codes: O33, L62, F13.

\footnotetext{
* We thank the editor, Aviv Nevo, and the three referees for outstanding comments and suggestions. We are also grateful to Kyle Bagwell, Allan Collard-Wexler, John Graham, Kenneth Hendricks, Tom Holmes, Cristian Huse, Ashley Langer, Amil Petrin, Jeff Prince, Bob Staiger, Frank Wolak as well as audiences at several seminars and conferences. We are solely responsible for any errors that may still remain. Moral gratefully acknowledges funding from the Spanish Ministry of Education and Science, and the European Regional Development Fund through grants ECO2017-82445-R and ECO2015-69334.

$\dagger$ The University of Texas at Austin, Department of Economics, 2225 Speedway Stop 3100, Austin, Texas 78712-0301; Centre for Competition Policy/UEA; and CEPR, London, UK. Phone: 512-232-1718. Fax: 512-471-3510. E-mail: miravete@eco.utexas.edu; http://www.eugeniomiravete.com

¥ Facultad de Ciencias Económicas y Empresariales, UNED, Paseo Senda del Rey, 11, 28040, Madrid, Spain; and GRiEE, Vigo, Spain; Phone: +34-91-398-8930. Fax: +34-91-398-7821. E-mail: mjmoral@cee.uned.es; http://webs.uvigo.es/mjmoral

$\S$ University of Notre Dame, Department of Economics, 3047 Nanovic Hall, Notre Dame, IN 46556. Phone: 574-6313083. E-mail: jthurk@nd.edu; http://www.nd.edu/ jthurk/
} 


\section{Introduction}

Multilateral trade agreements among countries have driven import tariffs to historic lows (Bergstrand, Larch and Yotov, 2015). When application of traditional protectionist policies such as tariffs and quotas becomes harder due to trade liberalization agreements, governments may resort to less obvious regulations designed to protect domestic industries (Bhagwati and Ramaswami, 1963; Staiger, 1995; Bagwell and Staiger, 2001; Ederington, 2001). In this paper we consider fuel taxation and vehicle emission regulations as examples of such policies employed by the European Union. We argue these policies had the effect of promoting diesel vehicles among consumers and thereby increased profits for the firms who offered diesels - European auto makers.

Our setting is the European marketplace where (largely) European diesel vehicles constitute the majority of new car sales. We show that diesel fuel was taxed at a lower rate than gasoline and the vehicle emissions policy chosen by European regulators targeted carbon monoxide $(C O)$ and carbon dioxide $\left(\mathrm{CO}_{2}\right)$ but not nitrogen oxide $\left(\mathrm{NO}_{x}\right) .{ }^{1}$ This distinction is important as diesel cars produce a large amount of $\mathrm{NO}_{x}$ emissions but relatively little $\mathrm{CO}$ and $\mathrm{CO}_{2}$. Gasoline-powered engines do just the opposite. Hence, these policies provided a competitive advantage for domestic auto makers as foreign firms sold gasoline-powered vehicles which not only used a more expensive fuel but also faced stricter emissions standards than their diesel-powered competition.

We use detailed automobile registration data from Spain - a country with diesel adoption rates representative of Europe - to estimate a structural discrete choice oligopoly model of horizontally differentiated goods similar to Berry, Levinsohn and Pakes (1995), henceforth BLP. The model is flexible enough to generate reasonable substitution patterns between similar products while accounting for product characteristics known to consumers and firms but not to the researcher. Our data have two important features. First, the sample covers the years immediately following the introduction of the turbodiesel engine in 1989 - a major improvement in diesel technology which proved to be very popular among consumers as diesel penetration increased from $10 \%$ to $50 \%$ in less than a decade. Second, the sample also covers a period in which European auto makers faced increased competition from Asian auto makers.

We show that fuel taxation and vehicle emissions standards chosen by European regulators promoted diesels through three channels. The first channel is consumer demand where our estimates indicate that consumers preferred vehicles with greater fuel economy defined as the number of kilometers one can travel per euro of fuel. Fuel economy is therefore a function of both fuel efficiency, defined as the number of kilometers one can travel on a liter of fuel, and fuel price where the latter is impacted by fuel taxes. A primary advantage of diesel cars is their superior fuel efficiency, traveling 20-40\% farther on a liter of fuel. Since they benefited from preferential European fuel taxes, the average diesel in our data could travel $63 \%$ farther per euro of fuel relative

${ }^{1} \mathrm{CO}$ and $\mathrm{CO}_{2}$ are greenhouse gases associated with global warming while $N O_{x}$ emissions are associated with smog and to a lesser extent acid rain. The role of $\mathrm{CO}$ as a greenhouse gas is weaker than $\mathrm{CO}_{2}$ though still relevant (see http://tes.jpl.nasa.gov/mission/climateroles). 
to a comparable gasoline-powered car. A stricter vehicle emissions policy would have eroded this advantage as the addition of sophisticated abatement technologies required to meet such a standard would have increased vehicle weight and decreased performance. These two policies therefore both worked to promote diesel vehicles by enhancing the fuel savings of diesels' superior fuel efficiency.

The second channel corresponds to the increased marginal cost required to meet a stricter $N O_{x}$ emissions policy. We document several different technologies capable of reducing $N O_{x}$ emissions though each increases production cost to diesel vehicles. In equilibrium, some of this expense would have been passed on to consumers through higher retail prices, leading some consumers to switch to models equipped with gasoline engines likely produced by foreign firms. By not choosing stricter $N O_{x}$ emissions standards, European regulators implicitly reduced the retail prices of diesel vehicles and increased the likelihood price-sensitive consumers would choose them.

The third channel addresses why these policies amounted to non-tariff trade policies. We argue that the popularity of diesel cars among European consumers is a unique feature of this market and we outline a variety of initial conditions which likely provided a foundation for the fast adoption of diesels in Europe. As the European market constituted the bulk of sales for domestic auto makers, developing a viable diesel technology was a worthwhile investment. Foreign firms on the other hand chose not to invest in the diesel technology since Europe constituted just a niche market for them. ${ }^{2}$ Policies favoring diesels thus benefited domestic firms almost exclusively.

We quantify the effects of alternative fuel taxation and vehicle emissions policies via counterfactual analysis. We show that diesels were not only popular among consumers, they also generated significant profits for European firms. Had regulators imposed fuel taxes and vehicle emissions standards which did not favor diesel vehicles, consumers would have substituted towards gasoline-powered Asian imports leading to significant reductions in profits for domestic automakers. Such a shift is usually achieved by levying import tariffs on foreign products leading to less consumption of foreign varieties. Multilateral negotiations over the past several decades, however, have driven import tariffs to record lows thereby reducing their effectiveness as a policy tool.

We use the estimated model to measure the implicit protective value of these policies, i.e., their tariff-equivalence. We find that only by imposing an import tariff of between $17.1-27.4 \%$, or roughly two to three times the official rate, could European regulators have both employed the alternative policies we consider and maintained the import share observed in the data. Moreover, we show both policies played important roles in protecting domestic firms. We view these results as evidence that national policies can indeed amount to significant non-tariff trade barriers.

Economists, policy experts, and politicians have all expressed concerns over the ability of national policies to fill the void left by import tariffs but identifying and quantifying effects of

${ }^{2}$ Kato (1997) recognizes the priority given by European regulators to $\mathrm{CO}_{2}$ over $\mathrm{NO}_{x}$ as well as the disinterest of Japanese firms to invest in an automobile technology (diesels) that was only popular in Europe. Busser and Sadoi (2004, Footnote 2) document that since demand was small in their countries of origin, Asian manufacturers such as Toyota chose to purchase diesel engines from other European firms as a less costly way to satisfy European demand rather than investing in the development of diesel engines from scratch. 
non-tariff barriers (NTBs) has proven difficult. Our results therefore amount to an important and novel contribution as, to the best of our knowledge, this study is the first to measure the effects of a non-tariff barrier using an estimated structural model. The advantage of our structural approach is that it enables us to account for the optimal equilibrium responses of consumers and firms to alternative policies, thereby increasing the reliability of our conclusions.

We are not the first to evaluate the trade effects of policy on heterogenous firms in the automobile industry. Feenstra (1988) documents that voluntary export restraints placed on Japanese cars during the 1980s and early 1990s induced significant quality-upgrading by Japanese firms leading to the growth of luxury brands Acura, Infiniti, and Lexus in the U.S. market. Berry, Levinsohn and Pakes (1999) show this policy also increased profits for domestic firms and decreased welfare for domestic consumers while leaving significant tariff revenue on the table. Goldberg and Verboven (2001) evaluate sources for cross-country dispersion of vehicle prices in Europe prior to 1993 while Goldberg and Verboven (2005) document that the creation of the European single market served to reduce price dispersion. Put differently, these papers document that the existence of different rules among European countries served to decrease competition. ${ }^{3}$ Our contribution is to evaluate the tariff-equivalence of domestic policies and thereby demonstrate that seemingly innocuous domestic policies can amount to significant trade policy.

We show our results are robust to a variety of alternative assumptions and that European firms would have had to increase the fuel efficiency of their gasoline fleet significantly to compensate for lost diesel profits under the alternative policies we consider. At the core of our hypothesis is the idea that national governments may set seemingly innocuous rules which benefit domestic firms at the expense of foreign ones. It is from this perspective that Volkswagen's recent admission to cheating on the U.S. Environmental Protection Agency's $N O_{x}$ emissions standards provides an unique external validation for our conclusions. ${ }^{4}$

First, the episode confirms that European firms like Volkswagen earned substantial profit from their diesel fleets and that stricter $N O_{x}$ standards both increase cost and decrease performance leading to less sales and lower profits. The fact that Volkswagen management was willing to risk severe financial punishment for cheating only reinforces this connection between diesel sales and vehicle emissions standards. ${ }^{5}$ Interestingly, the harsh prosecution of the case in the U.S. will also likely result in the effective disappearance of diesel vehicles from the U.S. market for a second time in two decades due to failure to meet American emission standards.

Second, Volkswagen's admission to also cheating on European emissions policy since 2004 elicited a very different response in Europe where regulators chose to increase the $N O_{x}$ ceiling

3 Jacobsen (2013), Goldberg (1998) and Ito and Sallee (2017) show the introduction of corporate average fuel economy (CAFE) standards in the United States favored foreign over domestic firms. Thus, the domestic policy they study actually promoted foreign imports.

${ }^{4}$ On September 18th, 2015 the United States Environmental Protection Agency (EPA) accused Volkswagen of devising a sophisticated scheme to deceive authorities when testing for nitrogen oxide $\left(N O_{x}\right)$ emissions.

5 The notice of violation, and VW's subsequent admission, translated into an immediate $20 \%$ drop in its stock market value due to concerns about the company's credibility as well as an estimated $\$ 18$ billion in fines. 
facing cars sold in Europe and government committed itself to not revisiting the policy until 2019. While the company also faces financial penalties in Europe, we view this as stark evidence that E.U. regulators understand that a stricter $N O_{x}$ emissions policy would have significant adverse effects on domestic firms.

It is tempting to view our results as an indictment of European policy or proof that European regulators explicitly designed their fuel taxes and emission standards to promote domestic automakers. Our point is that regardless of whether it was the intent of the policymaker, the effect of these policies served to protect domestic European manufacturers by fostering a preference for a technology, diesel engines, that was only produced by domestic firms. We show that, provided health and environmental externalities from diesel vehicle emissions were negligible, these policies actually benefited consumers as they promoted an innovation (diesels) valued by Europeans due fuel cost savings and relative affordability. Thus, it could be that these policies were enacted to serve consumers and inadvertently also protected domestic firms.

Lastly, we ask: Did these policies violate WTO rules? The WTO considers a policy a non-tariff barrier only if the policy is not "set at an appropriate level to achieve legitimate objectives with minimum impact on trade" (OECD, 2005). Thus, proving European fuel taxation and vehicle emission policies did indeed amount to illegal NTBs would have been difficult since European regulators could have claimed the policies benefited consumers. Our results therefore provide evidence that national policy can be an effective substitute for import tariffs and that proving such a policy amounted to an illegal NTB is difficult.

The paper is organized as follows. In Section 2, we describe the growth of diesel vehicles in Europe. In Section 3 we document differences in diesel and gasoline fuel taxes as well as discuss differences in emissions policy between the U.S. and Europe. Section 4 describes the equilibrium model of discrete choice demand for automobiles. Section 5 describes the estimation approach, discusses identification, and reports results. In Section 6, we use the estimated model to quantify the equilibrium implications of alternative fuel taxes and emissions policies on the European automobile market and calculate the tariff-equivalence of the pro-diesel regulations. Finally, Section 7 summarizes our contribution. Additional results, information, and data sources are documented in the Appendix.

\section{The European Market for Diesel Automobiles in the 1990s}

This section familiarizes the reader with the basic characteristics of the diesel technology; the institutional features of the European automobile market that allowed for a swift take off of diesel sales in the early 1990s; the evolution of the Spanish market; and characteristics of vehicles in the data. 


\subsection{A Significant Innovation - Next Generation Diesel Engines}

In the late 19th century, Rudolf Diesel designed an internal combustion engine in which heavy fuel self-ignites after being injected into a cylinder where air has been compressed to a much higher degree than in gasoline engines. However, it was only in 1927, many years after Diesel's death, that the German company Bosch built the injection pump that made the development of the engine for trucks and automobiles possible. The first commercial diesel vehicles followed soon after: the 1933 Citroën Rosalie and the 1936 Mercedes-Benz 260D. Large passenger and commercial diesel vehicles were common in Europe from the late 1950s through the 1990s.

In 1989, Volkswagen introduced the turbocharged direct injection (TDI) diesel engine in its Audi 100 model, a substantial improvement over the existing Perkins technology. ${ }^{6}$ A turbocharged diesel ("turbodiesel") engine uses a fuel injector that sprays fuel directly into the combustion chamber of each cylinder and the turbocharger increases the amount of air going into the cylinders. Complementing both is an intercooler which lowers the air temperature in the turbo thereby increasing the amount of fuel that can be injected and burned. The net effect was that these turbodiesel vehicles were significantly quieter, cleaner (no black smoke), and more reliable than their predecessors while maintaining superior fuel efficiency and torque relative to comparable gasoline models. ${ }^{7}$

Other European firms quickly introduced their own turbodiesels, most notably Peugeot and Renault. ${ }^{8}$ The incredible pace of adoption of diesel automobiles, growing from $10 \%$ to nearly $60 \%$ market share within a decade, suggests that the turbodiesel technology proved to be a significant technological advance and that consumers gained little from waiting for additional incremental improvements, which have been few and of minor importance. ${ }^{9}$

\subsection{The Automobile Industry in the 1990s}

Our data include yearly car registrations by manufacturer, model, and fuel engine type in Spain between 1991 and 2000. After removing a few observations, mostly of luxury vehicles, our sample is an unbalanced panel comprising $99.2 \%$ of all car registrations in Spain during the 1990s. Spain was the fifth largest automobile manufacturer in the world during the 1990s and also the fifth largest European automobile market by sales after Germany, France, the United Kingdom, and Italy. ${ }^{10}$ In our sample automobile sales range from 873,057 to $1,364,687$ units sold annually.

${ }^{6}$ The 1987 Fiat Croma was actually the first diesel passenger car to be equipped with turbo direct-injection. Whereas the Audi 100 controlled the direct injection electronically, the Fiat Croma was mechanical. The difference proved crucial for commercial success as electronic controls improved both emissions and power.

7 See the 2004 report "Why Diesel?" from the European Association of Automobile Manufacturers (ACEA).

8 Thurk (2017) evaluates the financial implications for VOLKSWAGEN due to the quick imitation of the TDI.

9 This argument was first put forward by Schumpeter (1950, p.98) and later formalized by Balcer and Lippman (1984). More recently, it has been used by Manuelli and Seshadri (2014) to explain the half a century time span needed for the diffusion of the much studied case of tractors.

${ }^{10}$ See Appendix A for further details on Spanish data sources. 


\section{Figure 1: Trends in the European Automobile Market}

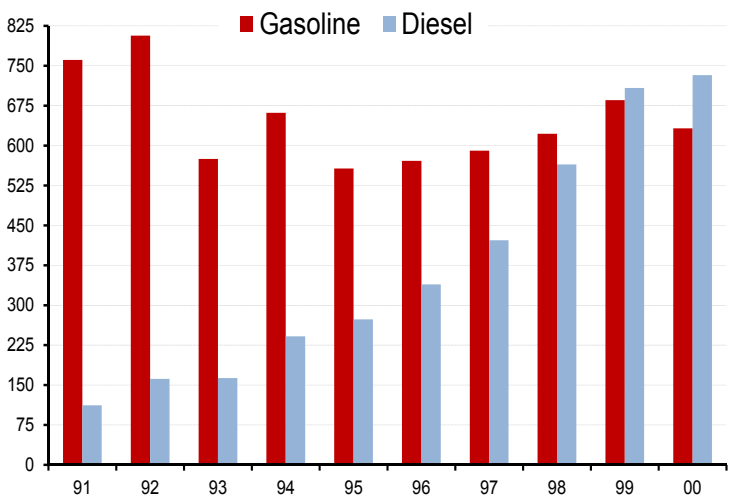

(a) Sales (thousands of vehicles)

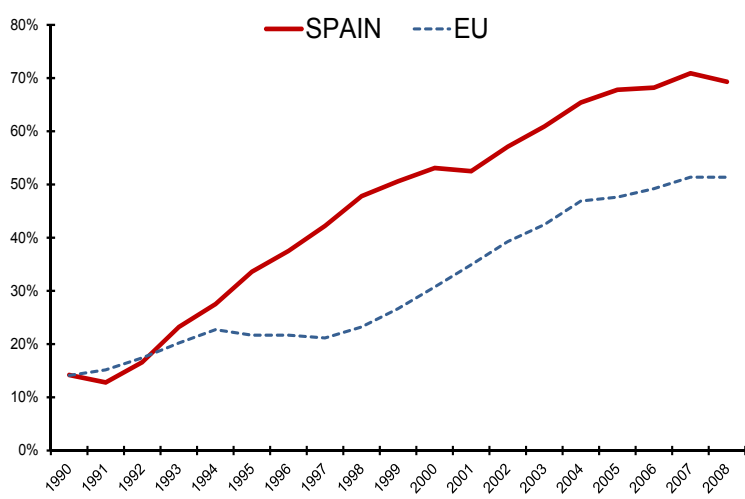

(b) Diesel Penetration

Notes: Authors' calculations. New passenger car registration data from Association Auxiliaire de l'Automobile (AAA). In panel (b), we constructed European diesel penetration (dashed line) using gross domestic product as weights (source: World Bank Development Indicators). Countries included: Austria, Belgium, Denmark, France, Germany, Ireland, Italy, Luxembourg, Netherlands, Portugal, and the United Kingdom.

Figure 1 (a) depicts the growth and changing composition of the Spanish automobile market. Sales of gasoline models were flat in 1993 and 1995, about 573,000 vehicles, despite a scrappage program in 1994, when they temporarily increased by $15 \%$. Sales of gasoline models has grown steadily since, but this growth pales in comparison to the growth of diesels. Initially in 1991, they only represented about $13 \%$ of total sales but by the end of the decade diesels represented $54 \%$ of the market, growing from 111,943 to 732,334 units sold in years 1991 and 2000, respectively. Figure 1 (b) shows that diesel vehicles became increasingly popular not only in Spain but all over Europe. $^{11}$

In Table 1 we document the dramatic transformation in the number and characteristics of vehicles available to consumers where we present vehicle characteristics as the sales-weighted average to account for changes in consumer demand. At the beginning of the decade consumers could choose from 129 different models, most of which were produced by domestic automakers. By 2000 the consumer's choice set had grown substantially (from 129 to 229 vehicles) driven largely by the entry of gasoline vehicles by Asian automakers. ${ }^{12}$ At the same time foreign firms were entering the European market, domestic automakers increased their supply of diesel vehicles. In 1991 a consumer interested in purchasing a diesel could choose from 43 different options where all but one

${ }^{11}$ There is variance in the adoption of diesels across countries, however, as smaller countries such as Denmark were slow adopters while France, led by Peugeot, adopted diesels earlier than Spain.

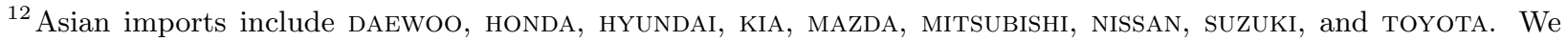
use the terms "Asians" or "non-Europeans" when referring to imports. Appendix B documents that most Asian automobiles were directly imported into the European market and that the small production of Asian automobiles in Europe, transplants, was generally treated as imports until year 2000 because of their limited "local content" in terms of value added. We thus treat them as imported products. CHRYSLER sold its production facilities to PEUGEOT in 1978 and since then the few models sold in Europe are imported from the United States. On the contrary FORD and GM are considered European manufacturers. FORD has 12 manufacturing plants and has been continuously present in Europe since 1931. GM entered the European market in 1911, acquired the British brand Vauxhall and the German Opel in the 1920s and today operate 14 manufacturing facilities in Europe. In both cases, these brands have factories in Spain. 
Table 1: Car Model Characteristics by Origin and Engine Types

\begin{tabular}{lrrrrrrrr}
\hline \hline 1991 & MODELS & SHARE & PRICE & SIZE & HPW & C90 & MPG & KPE \\
\hline EU: DIESEL & 42 & 12.78 & 12.09 & 73.18 & 3.09 & 4.42 & 53.85 & 46.82 \\
EU: GASOLINE & 68 & 84.08 & 10.85 & 71.03 & 4.09 & 5.31 & 45.10 & 30.05 \\
NON-EU: DIESEL & 1 & 0.04 & 13.76 & 80.51 & 2.86 & 5.30 & 44.38 & 38.58 \\
NON-EU: GASOLINE & 18 & 3.10 & 15.16 & 78.16 & 4.50 & 5.71 & 41.60 & 27.72 \\
\hline ALL & 129 & 100.00 & 11.15 & 71.53 & 3.97 & 5.21 & 46.11 & 32.13 \\
\hline \multicolumn{1}{r}{} & & & & & & & \\
\hline \hline 2000 & MODELS & SHARE & PRICE & SIZE & HPW & C90 & MPG & KPE \\
\hline EU: DIESEL & 75 & 50.95 & 16.19 & 76.32 & 3.14 & 4.55 & 52.35 & 38.18 \\
EU: GASOLINE & 84 & 37.28 & 14.93 & 73.40 & 3.90 & 5.68 & 41.89 & 24.23 \\
NON-EU: DIESEL & 20 & 2.71 & 17.20 & 82.48 & 3.22 & 5.41 & 44.74 & 32.63 \\
NON-EU: GASOLINE & 50 & 9.06 & 13.66 & 75.32 & 4.08 & 6.11 & 39.41 & 22.80 \\
\hline ALL & 229 & 100.00 & 15.52 & 75.31 & 3.51 & 5.13 & 47.07 & 31.43 \\
\hline
\end{tabular}

Notes: Statistics weighted by quantity sold. SHARE is the market share as defined by automobiles sold. PRICE is denominated in the equivalent of thousands of 1994 Euros and includes value added taxes and import tariffs. SIZE is length $\times$ width measured in square feet. HPW is the performance ratio of horsepower per hundred pounds of weight. C90 is consumption (in liters) of fuel required to cover $100 \mathrm{~km}$ at a constant speed of $90 \mathrm{~km} / \mathrm{hr}$. MPG is the number of miles one can travel on a gallon of fuel. KPE is the distance, measured in kilometers, traveled per euro of fuel. Table A.2 in Appendix A complements this description of product features reporting statistics by market segment.

was produced by a European firm. By 2000 this consumer had 95 different diesel options, of which 75 were produced by a European automaker. Thus, not only were diesels very popular among European consumers they were also produced almost entirely by European firms.

Diesel and gasoline versions of a particular car model share the same chassis, so a consumers compare performance rather than car size or appearance when deciding whether to buy a diesel or gasoline-powered vehicle. Diesel engines are about 10\% heavier than a comparable gasoline engine; have $15 \%$ to $20 \%$ less horsepower than gasoline engines; and are between one and two thousand euros more expensive. Diesel vehicles also consume 20\%-40\% less fuel than a comparable gasoline model, and given that diesel fuel is less expensive than gasoline due to differences in taxation, the average diesel in our data travels about $63 \%$ farther on a euro of fuel than a comparable gasoline-powered model. We observe that cars generally become less fuel efficient over the sample (e.g., the fuel efficiency for European diesels decreases from 53.85 to 52.35 miles/gallon) but the increasing popularity of diesels ultimately increased the average fuel efficiency (MPG) on the road from 46.11 to 47.07 miles/gallon over the sample. We also observe that cars become on average $39.2 \%$ more expensive, $5.5 \%$ larger, and $11.6 \%$ less powerful (HPW) across time.

Our final observation relates to the market entry of fuel-efficient Asian (NON-EU) vehicles, particularly in the gasoline segment. This entry eroded market share for European firms where domestic automakers accounted for $84 \%$ of all sales in the gasoline segment but only $37 \%$ by 2000 . Their investment in diesel vehicles and subsequent dominance in that segment, however, mitigated the effects of foreign competition overall as European automakers accounted for $88 \%$ of all sales in 2000, down slightly from $97 \%$ in 1991. Thus, diesel vehicles appear to have been a significant competitive advantage for domestic automakers in fending off foreign competition. 


\section{Why Are Diesels Popular in Europe?}

In this section we put forward two hypotheses as to why diesel vehicles have been and remain popular among European consumers. Our first hypothesis is that pro-diesel fuel excise taxes enacted in the 1970s to support the transportation and agricultural industries acted as a catalyst for consumer adoption of diesel vehicles. As turbodiesels became popular in the 1990s, an emissions standards policy which favored diesel vehicles then served to promote the technology as well as protect domestic automakers - our second hypothesis. We test these hypotheses in Section 6 .

\subsection{Preferential Fuel Taxes}

There are important institutional circumstances that helped build the initial conditions that were particularly favorable for the adoption of this new technology in Europe. The key element is the European Fuel Tax Directive of 1973 adopted by the then nine members of the European Economic Community gathered in Copenhagen in December of 1973, two months after the oil crisis began. The main goal was to harmonize fuel taxation across countries so that drivers, and fossil fuel users in general, faced a single and consistent set of incentives to save energy. Coordination also limited the possibility of arbitrage across state lines as well as prevented countries from free-riding on the conservation efforts of other members. Neither fuel prices nor their taxation were harmonized overnight but the new Tax Directive offered principles of taxation that were eventually followed in every country.

Regulators designed policy to help two economic industries particularly hit by the increase in 1970s oil prices: road transport and agriculture. With minor modifications, these principles have guided European fuel taxation until very recently. In 1997 the European Commission first suggested modifying these principles of taxation to reduce the differential treatment of diesel and gasoline fuels and incorporating elements of environmental impact of each type of fuel when setting taxes. This change in principles was only adopted in 2013, however, so consumers faced stable and consistent incentives favoring diesel fuel consumption for a very long period of time. ${ }^{13}$

For the purposes of this study, there are two important features of European policy. First, is the decision by regulators to tax fuel by volume rather than by their energetic content. While taxing fuels by volume offers a transparent criteria to monitor national policies, it also benefits diesel vehicles as diesel fuel has a greater energetic potential than gasoline (129,500 BTU per gallon vs. gasoline's 114,000). Second, regulators chose to tax diesel fuel at a lower rate than gasoline a point illustrated in Figure 2 where in our sample the diesel tax amounted to $69 \%$ of the gasoline tax (32 vs. 46 Euro cents per liter) leading to systematically lower diesel fuel price for consumers. At a time when there was concern over the limited availability of low cost oil, the proponents of diesel cited the superior fuel efficiency (i.e., miles per gallon) of diesels as a way to conserve oil.

\footnotetext{
${ }^{13}$ See http://ec.europa.eu/taxation_customs/taxation/excise_duties/energy_products/legislation/index_ en.htm for a complete description of the European Fuel Tax Directive and its evolution over time.
} 
Figure 2: Fuel Prices Gross and Net of Taxes (1994 Euro-cents/liter)

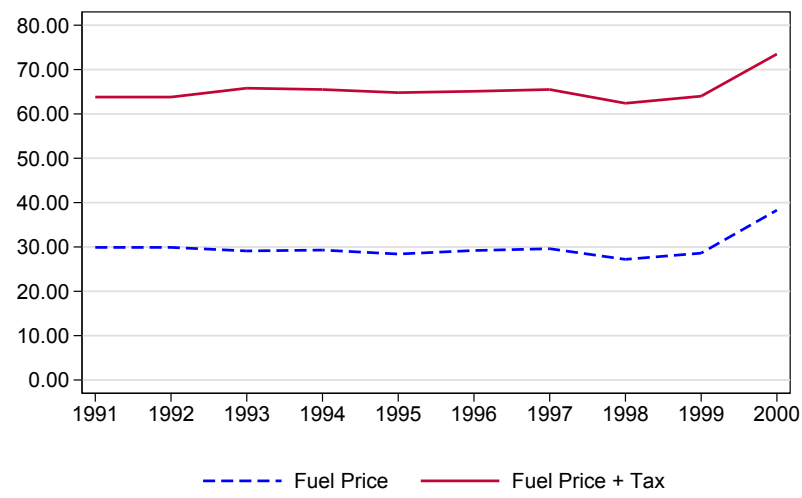

(a) Gasoline

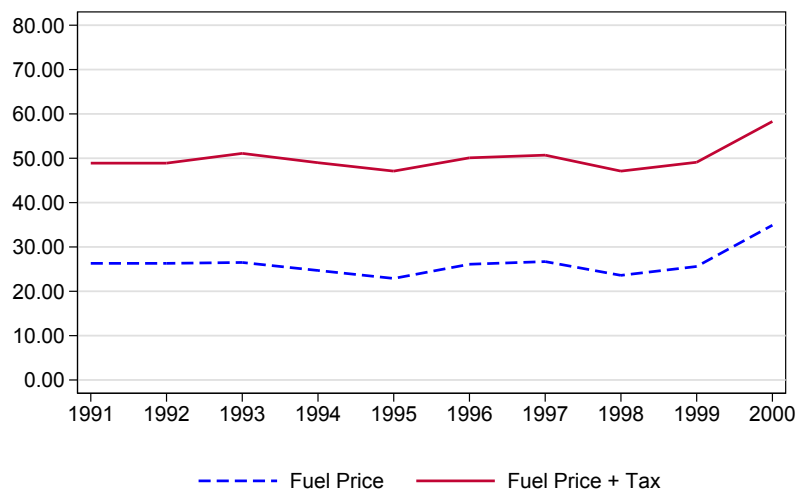

(b) Diesel

This favorable tax treatment of diesel fuel fostered the sale of diesel vehicles from the mid-1970s in Europe. By the end of the 1980s, some large passenger cars and many commercial vehicles comprising almost $10 \%$ of the market ran on diesel fuel. Thus, when the TDI was first sold in 1989, Europeans, unlike Americans, were familiar with diesels and did not have a particularly negative perception of the quality of diesel vehicles. ${ }^{14}$ More importantly, Europeans did not have to cope with the additional network costs commonly delaying the adoption of alternative fuels: by 1990 diesel pumps were ubiquitous, indeed available in every gas station, and it was easy to find mechanics trained to service these vehicles in case repairs were needed.

Initial conditions were thus more conducive to the success of the turbodiesel technology in Europe than in any other automobile market. And yet, it was not obvious that consumers were going to end up embracing this new technology when VOLKSWAGEN introduced the TDI engine. Diesels are known to achieve better mileage than otherwise identical gasoline vehicles, leading to future fuel cost savings, but they are also more expensive to purchase, presumably due to higher production costs or because manufacturers' attempt to capture consumer rents of drivers favoring diesel vehicles. ${ }^{15}$ Thus, to what extent can preferential fuel taxes explain the popularity of diesels in Europe? Had European regulators chosen to tax diesels at a higher rate, would this policy have eliminated any chance of success for diesels in Europe?

\subsection{Preferential Vehicle Emissions Standards}

Next we argue that the popularity of diesels in Europe was also due to vehicle emissions standards which favored diesel vehicles as they produce a different emission mix than gasoline models, i.e., diesel cars produce a large amount of $\mathrm{NO}_{x}$ and little $\mathrm{CO}$ and $\mathrm{CO}_{2}$ while gasoline engines do just

\footnotetext{
${ }^{14}$ See http://www. autosavant.com/2009/08/11/the-cars-that-killed-gm-the-oldsmobile-diesel/ for an account of how badly GM's modified gasoline engines delivered poor performance when running on diesel fuel in the late 1970s and early 1980s and how such experience conformed the negative views of Americans on diesel vehicles for many years.

${ }^{15}$ Verboven (2002) analyzes the price premium of diesel vehicles relative to otherwise identical gasoline model, as a business strategy aimed to capture some of the rents of consumers with heterogeneous driving habits.
} 


\section{Figure 3: Europe and U.S. Emissions Standards}
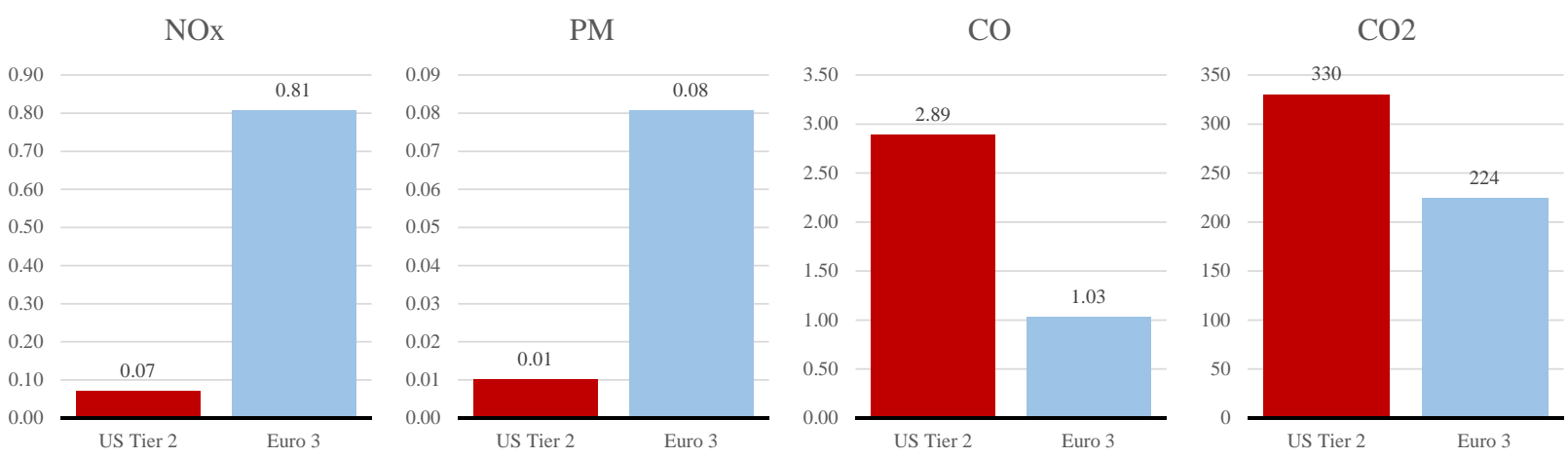

Source: www.dieselforum.org. "NOx" refers to nitrogen oxide limits; "PM" to particulate matter; "CO" carbon monoxide; and "CO2" carbon dioxide. U.S. statistics for $N O_{x}, P M$, and $C O$ are based on fleet averages under Tier 2 of the 1990 Clean Air Act Amendments (CAAA) while the statistic for $\mathrm{CO}_{2}$ is based on a CAFE standard of 27.5 mpg. E.U. statistics for $\mathrm{NO}_{x}, P M$, and $C O$ are based on the Euro III standards implemented in 2000 while the $C_{2}$ statistic is the 2008 fleetwide commitment. Prior to 2008 the E.U. did not regulate $\mathrm{CO}_{2}$ emissions. All statistics are in grams of emissions per mile driven.

the opposite. In Figure 3 we document that American and European regulators chose to target different kinds of vehicle emissions. In The U.S. approval of the 1990 Clean Air Act Amendments (CAAA) directed the U.S. Environmental Protection Agency (EPA) to reduce smog produced by nitrogen oxide $\left(N \mathrm{O}_{x}\right)$ and acid rain produced by sulfur dioxide $\left(\mathrm{SO}_{2}\right)$. The EPA therefore chose a policy which set stringent $N O_{x}$ vehicle emissions standards but weaker limits on $C O$ and $C_{2} \cdot{ }^{16,17}$

Europeans did just the opposite and chose less stringent targets for $N O_{x}$ emissions and particulate matter, $P M{ }^{18,19}$ In 1994 U.S. Tier 1 standard allowed $N O_{x}$ emissions of 1 gram per mile $(\mathrm{g} / \mathrm{mi})$ while the Euro I standard was $1.55 \mathrm{~g} / \mathrm{mi}$. By year 2000 U.S. policy allowed only $0.07 \mathrm{~g} / \mathrm{mi}$ while the Euro III standard set the $N O_{x}$ emission level at a far less demanding $0.81 \mathrm{~g} / \mathrm{mi}$. Similar results hold for $P M$. The fast diffusion of diesel vehicles in the 1990s also enabled European authorities to choose more stringent $\mathrm{CO}_{2}$ emission standards than the United States; the goals of local automobile manufacturers and European environmental regulators were thus perfectly aligned.

${ }^{16}$ For simplicity we refer to the EPA setting US policy but a more accurate depiction center on the the California Air Resources Board (CARB) as the driving force for a stricter $N O_{x}$ vehicle emission standard as the combination of westerly prevailing winds, eastern mountains in California, and large population centers like Los Angeles led to significant concerns over smog in the state.

${ }^{17}$ The EPA set its emissions goals (Title IV-A) targeting power generating plants and established a cap-and-trade system (Title V). The EPA also chose strict $N O_{x}$ emission standards for light-duty vehicles (Title II-A).

${ }^{18}$ European authorities set $N O_{x}$ and $P M$ standards for each vehicle while U.S. authorities set a fleet-wide limit. As for $\mathrm{CO}$ and $\mathrm{CO}_{2}$ emissions, these depend on fleet average fuel consumption standards and are reported as realized fleet-wide levels.

${ }^{19}$ See Section IV of the 2001 report: "Demand for Diesels: The European Experience. Harnessing Diesel Innovation for Passenger Vehicle Fuel Efficiency and Emissions Objectives" available at www.dieselforum. org. The negative health effects of $P M$ are well documented. Capturing $P M$ is however easier and far less expensive than capturing $N O_{x}$ and we will not address it in our counterfactual analysis. See The World Bank's report: Reducing Black Carbon Emissions from Diesel Vehicles: Impacts, Control Strategies, and Cost-Benefit Analysis available at https ://openknowledge.worldbank.org/bitstream/handle/10986/17785/ 864850WP0OPUBL010report002Apri12014.pdf. In page 27 it indicates that the cost of complying with the most stringent $P M$ emissions for a 4-cylinder 1.5 L diesel engine was \$1,400 in 2014. 
The differences between the U.S. and European emission standards are significant. Reducing $N O_{x}$ emissions is much harder for diesel engines as the three-way catalytic converters used to reduce emissions in gasoline engines cannot cope with the high concentrations of $N O_{x}$ generated by diesel engines, e.g., Canis (2012). Thus, for instance, in the 1990s, rather than investing to redesign their diesel engines to meet these stringent emission standards, VOLKSWAGEN and MERCEDES chose to stop selling their diesel models in the U.S. market in 1993 and 1994, respectively, precisely at the time of the implementation of the U.S. emission standards mandated by the CAAA. ${ }^{20}$

Only in 2009 did the EPA finally address the issue of $N O_{x}$ emissions from diesel vehicles by requiring the installation of an urea-based selective catalytic reduction (SCR) that injects an aqueous solution into the vehicles' exhaust stream to "scrub" $N O_{x}$ emissions, e.g., Appendix C. An SCR system not only increases a car's manufacturing cost, it also increases the vehicle's weight and therefore decreases fuel efficiency. There is also evidence that operating the system decreases performance in other dimensions. ${ }^{21}$ Whether turbodiesels will remain a viable product in the U.S. market is unclear. Moreover, the impact of vehicle emissions on vehicle sales suggests that American emission standards amounted to a de facto ban of diesel vehicles in the U.S. market. Could then a similar European emission policy have eliminated any chance of success for diesels in Europe?

\section{An Equilibrium Oligopoly Model of the Automobile Industry}

In this section we present a structural model of demand and supply to conduct our analysis. We first present a $B L P$ discrete choice demand for horizontally differentiated products with heterogenous preferences over observable and unobservable automobile characteristics. We add to this a model of oligopoly Bertrand-Nash price competition among multi-product firms. The model delivers a set of structural equations which we use to recover the underlying demand and cost parameters.

\subsection{Demand}

Demand can be summarized as follows: consumer $i$ derives an indirect utility from buying vehicle $j$ at time $t$ that depends on price and characteristics of the car:

$$
\begin{aligned}
& u_{i j t}=x_{j t} \beta_{i}+\alpha_{i t} p_{j t}+\xi_{j t}+\epsilon_{i j t}, \\
& \text { where } i=1, \ldots, I_{t} ; \quad j=1, \ldots, J_{t} ; \quad t=\{1991, \ldots, 2000\}
\end{aligned}
$$

\footnotetext{
${ }^{20}$ According to Stewart (2010), the $N O_{x}$ emissions level of the least polluting diesel model available in Canada, the volKSWAGEN Jetta (known as Bora in Europe), was 0.915 and $0.927 \mathrm{~g} / \mathrm{mi}$ for the 1991 and 1997 year models, respectively. This indicates that the $N O_{x}$ emissions standards imposed by the EPA were indeed binding constraints for diesel vehicles since even the cleanest diesel models barely met the 1994 U.S. emission standards and would have generated $N O_{x}$ emissions thirteen times greater than the 2000 limit.

${ }^{21}$ See the April 2016 report "Volkswagen Diesel Emissions Settlement High on Promise, Short on Details." (https://www.consumerreports.org/cars-vw-fix-for-diesel-vehicles/). VOLKSWAGEN argues that the fix applied to the TDI has no impact on fuel efficiency or performance though road tests appear to contradict the company's claim (http://www.motortrend.com/news/ diesel-fix-reduces-fuel-economy-on-european-vw-model-test-shows/).
} 
where we define a product $j$ as model-engine type pair. In this Lancasterian approach, utility depends on the set of characteristics of the vehicle purchased which includes a vector of $K$ observable characteristics $x_{j t}$ as well as other characteristics which are known to consumers and firms but remain unobservable for the econometrician, $\xi_{j t}$. Unobserved tastes of consumer $i$ for vehicle $j$, $\epsilon_{i j t}$, follow an i.i.d. multivariate type I extreme value distribution. Similar to Sweeting (2013) we assume the unobserved quality $\xi_{j t}$ evolves according the following $\operatorname{AR}(1)$ process:

$$
\xi_{j, t+1}=F_{j}+S_{j}+\rho_{\xi} \xi_{j, t}+\nu_{j, t+1}
$$

where $F_{j}$ is a time-invariant brand (e.g., VOLKSWAGEN) fixed effect that captures differences in product quality levels across brands, $S_{j}$ is a time-invariant segment (e.g., COMPACT) fixed effect that captures differences in product quality across segments, and $\nu \sim N\left(0, \sigma_{\nu}^{2}\right)$ are temporary product-level demand shocks. This specification accounts for gradual unobserved improvements in quality that are the result of investment and cumulative experience of manufacturers, a reasonable approach when automakers are deploying new diesel models characterized by unobservable performance features such as high torque at low r.p.m., extended durability, and great reliability. As in Schiraldi (2011), $\nu$ represents unexpected innovations in unobserved quality that drives demand.

We allow for individual heterogeneity in response to vehicle prices and characteristics by modeling the distribution of consumer preferences over characteristics and prices as multivariate normal with a mean that shifts with consumer attributes:

$$
\begin{aligned}
\alpha_{i t} & =\alpha / y_{i t}, \\
\beta_{i} & =\beta+\Sigma \eta_{i}, \quad \eta_{i} \sim N\left(0, I_{n+1}\right) .
\end{aligned}
$$

Consumer $i$ in period $t$ is characterized by her income $y_{i t}$ as well as a vector of random tastes, $\eta_{i}$, distributed i.i.d. standard normal. $\Sigma$ measures the covariance in unobserved preferences across characteristics. The inclusion of these random coefficients generates correlations in utilities for the various automobile alternatives that relax the restrictive substitution patterns generated by the Independence of Irrelevant Alternatives property of the multinomial logit model.

We decompose the deterministic portion of the consumer's indirect utility into a common part shared across consumers, $\delta_{j t}$, and an idiosyncratic component, $\mu_{i j t}$. The mean utilities of choosing product $j$ and the idiosyncratic deviations around them are given by:

$$
\begin{aligned}
\delta_{j t} & =x_{j t} \beta+\xi_{j t}, \\
\mu_{i j t} & =\alpha / y_{i t}+x_{j t} \Sigma \eta_{i} .
\end{aligned}
$$

Each period $t, M_{t}$ consumers each choose to purchase either one of the $J_{t}$ vehicles available or the outside option $(j=0)$ of not buying a new car. We normalize the value of the outside option 
to be zero. ${ }^{22}$ We therefore define the set of individual-specific characteristics leading to the optimal choice of car $j$ as:

$$
A_{j t}\left(x_{\cdot t}, p_{\cdot t}, \xi_{\cdot t} ; \theta\right)=\left\{\left(y_{i t}, \eta_{i t}, \epsilon_{i j t}\right) \mid u_{i j t} \geq u_{i k t} \quad \forall k=0,1, \ldots, J_{t}\right\}
$$

with $\theta$ summarizing all model parameters. The extreme value distribution of random shocks allows us to integrate over the distribution of $\epsilon_{i t}$ to obtain the probability of observing $A_{j t}$ analytically. The probability that consumer $i$ purchases automobile model $j$ in period $t$ is:

$$
s_{i j t}=\frac{\exp \left(\delta_{j t}+\mu_{i j t}\right)}{1+\sum_{k \in J_{t}} \exp \left(\delta_{k t}+\mu_{i k t}\right)} .
$$

Integrating over the distributions of consumer income $y_{i t}$ and unobservable consumer attributes $\eta_{i t}$, denoted by $P_{y}\left(y_{t}\right)$ and $P_{\eta}\left(\eta_{t}\right)$, respectively, leads to the model prediction of the market share for product $j$ at time $t$ :

$$
s_{j t}\left(x_{t}, p_{t}, \xi_{t} ; \theta\right)=\int_{\eta_{t}} \int_{y_{t}} s_{i j t} d P_{y_{t}}\left(y_{t}\right) d P_{\eta_{t}}\left(\eta_{t}\right)
$$

with $s_{0 t}$ denoting the market share of the outside option.

\subsection{Pricing}

Equilibrium prices are found as the solution to a non-cooperative Bertrand-Nash game among the competing automakers. A firm $f$ maximizes period $t$ profits by choosing the vector of pre-tariff prices $p_{j t}^{w}$ for all of the products in its portfolio $J_{t}^{f}$. Going forward we drop time subscripts for the sake of brevity. Equilibrium pre-tariff prices $\left(p_{j}^{w}\right)$ can therefore be written as a nonlinear function of the product characteristics $(x)$, market shares $s_{j}(x, p, \xi ; \theta)$, retail prices $(p)$, and markups:

$$
p_{j}^{w}=m c_{j}+\underbrace{\Delta^{-1}(p, x, \xi ; \theta) s_{j}(p, x, \xi ; \theta)}_{b_{j}(p, x, \xi ; \theta)} ;
$$

where $p_{j}=p_{j}^{w} \times\left(1+\tau_{j}\right)$ and $\tau_{j}$ is the import duty applicable to model $j$, if any. The vector of equilibrium euro markups $b_{j}(\cdot)$ depends on market shares $s_{j}(\cdot)$ and the matrix $\Delta(\cdot)$ with elements:

$$
\Delta_{r j}(x, p, \xi ; \theta)=\left\{\begin{array}{cc}
\frac{\partial s_{r}\left(x, p, \xi_{t} ; \theta\right)}{\partial p_{j}} \times \frac{\partial p_{j}}{\partial p_{j}^{w}}, & \text { if products }\{r, j\} \in J^{f} \\
0 & \text { otherwise } .
\end{array}\right.
$$

\footnotetext{
${ }^{22}$ The data does not allow us to adequately model the used car market, e.g., Gavazza, Lizzeri and Roketskiy (2014), so our definition of the outside option combines consumers who do not buy a car with those who choose to buy a used car rather than a new car. Appendix A documents how we account for variation of the outside option over the economic cycle in Spain during the 1990s.
} 
Thus a firm f's optimal choice of pre-tariff prices internalizes the official tariff rate (if applicable) as well as the cross-price elasticities of products in its portfolio $\left(J^{f}\right)$.

In estimating costs we make a common assumption that firms have Cobb-Douglas cost functions, therefore:

$$
\log c=Z \gamma+\omega
$$

where $Z$ is composed of brand and segment fixed effects as well as logged observable characteristics while $\omega$ are cost components unknown to the researcher.

\section{Estimation}

We define the structural parameters of the model as $\theta=\left[\alpha, \beta, \gamma, \Sigma, \rho_{\xi}, \sigma_{\nu}^{2}\right]$ and construct the demand-side structural error by creating quasi-differenced moments of consumer mean utility (4a) taking advantage of the $\mathrm{AR}(1)$ process in which unobserved product quality evolves:

$$
\delta_{j t}\left(\Sigma, \alpha ; s_{j t}\right)-\rho \delta_{j, t-1}\left(\Sigma, \alpha ; s_{j, t-1}\right)=x_{j t} \beta-\rho x_{j, t-1} \beta+F_{j}+S_{j}+\nu_{j t} .
$$

Define the demand-side structural error as $\varepsilon^{D}(\theta)=\nu$ and the supply-side structural error as $\varepsilon^{S}(\theta)=\omega$. We construct these structural errors as follows. First we solve for the mean utilities $\delta(\theta)$ via a contraction mapping which connects the predicted purchase probabilities in the model to observed shares in the data for a given value of $\theta$ (see Berry, 1994 and $B L P$ ). We construct predicted aggregate shares (7) via Monte Carlo integration using 6,000 Halton draws. The demand-side structural error $\varepsilon^{D}$ then follows from (11). ${ }^{23}$ Observed prices, ownership structure, and tariff rates plus equation (8) generate marginal costs as a function of the parameter guess. The supply-side structural error $\varepsilon^{S}$ then follows from (10).

We make the common assumption that the product set is exogenous so that our structural errors are mean independent of the product characteristics, i.e., $E[\omega \mid Z]=0$ and $E[\nu \mid X]=0 .{ }^{24}$ Demand and supply parameter estimates $\theta=\left[\alpha, \beta, \gamma, \Sigma, \rho_{\xi}, \sigma_{\nu}^{2}\right]$ are recovered via a generalized method of moments (GMM) estimator using observable product characteristics as basis functions to construct identifying moment conditions $H$. The GMM estimator exploits the fact that at the true value of parameters $\left(\theta^{\star}\right)$, the instruments $H$ are orthogonal to the structural errors $\varepsilon^{D}\left(\theta^{\star}\right), \varepsilon^{S}\left(\theta^{\star}\right)$ so that the GMM estimates solve:

$$
\hat{\theta}=\underset{\theta}{\operatorname{argmin}}\left\{g(\theta)^{\prime} H W H^{\prime} g(\theta)\right\}
$$

\footnotetext{
${ }^{23}$ When we observe a vehicle for the first time, the analog to $(11)$ is $\varepsilon_{j t}^{D}(\theta)=\delta_{j t}(\theta)-x_{j t} \beta-F_{j}-S_{j}$ where our assumption is that these temporary demand shocks are also i.i.d. $N\left(0, \sigma_{\nu}^{2}\right)$.

${ }^{24}$ There are no automobile models sold exclusively in Spain but rather all are sold across the European continent. This reduces the concerns that product characteristic $X$ may be endogenous and responding to local demand.
} 
where $g(\theta)$ is a stacked vector of the demand and supply-side structural errors and $W$ is the weighting matrix, representing a consistent estimate of $E\left[H^{\prime} g g^{\prime} H\right]{ }^{25}$

Knittel and Metaxoglou (2014) and Dubé, Fox and Su (2012) point out that finding a global solution to (12) is difficult since the objective function is highly non-linear so any line, gradient, or simplex search will likely only result in a local solution. To increase the likelihood of achieving a global minimum, we employ a state-of-the-art minimization algorithm (Knitro Interior) starting from several different initial conditions - a strategy shown by Dubé et al. (2012) to generate the global solution in Monte Carlo simulations.

Specification. Consumer demand includes measures of automobile performance: horsepower divided by weight (HPW), exterior dimensions (SIZE), fuel economy (KPE), and engine type (DIESEL) where the inclusion of DIESEL as a random coefficient allows for different substitution patterns within the diesel segment. We also include a linear diesel trend (DIESEL $\times$ TREND) in mean utility which we found helpful in explaining the increasing popularity of diesel vehicles over time. We include brand fixed effects (e.g., AUDI, TOYOTA) to account for quality differences across brands and segment fixed effects (e.g., COMPACT, SEDAN) to capture segment-specific mean utility differences beyond HPW, SIZE, or KPE. We simulate individual income $y_{i t}$ from yearly census data to account for changes in the distribution of income across time. Finally, the inclusion of a linear time TREND accounts for any variation in the remaining relative valuation of the outside option over time.

In modeling supply we assume that marginal cost is a function of logged HPW, SIZE, and fuel efficiency. In contrast to consumer demand we replace KPE for C90 to eliminate the effect of fluctuations in fuel price, which has nothing to do with the cost of manufacturing engines. Consequently, AUDI's fuel-efficiency for a gasoline model A4 impacts its cost directly as measured by C90, but demand for A4's will also be influenced by changes in the price of gasoline (Figure 2) due to economic factors outside of AUDI's control through KPE. Similarly, we interact an index for the price of steel, SPI, with HPW and SIZE to account for the changes in the cost of this input. ${ }^{26}$ This impacts the value of HPW and SIZE in supply but not demand. We also include a DIESEL dummy to account for differences in engine cost as diesel engines are manufactured to withstand higher compression ratios during internal combustion. We include linear trends gasoline and diesel to capture changes in production marginal cost across the sample. As in the demand specification we include brand and segment dummies to account for differences in marginal cost across these dimensions. Finally, changes in import tariff rates are accounted for in $p$ through pricing equation (8) while changes in firm ownership due to mergers and acquisitions documented in Appendix A (Table A.1) impact the $\Delta$ matrix and ultimately estimated marginal costs also through equation (8).

25 In constructing the optimal weighting matrix, we first assume homoscedastic errors and use $W^{\prime}=\left[H^{\prime} H\right]^{-1}$ to derive initial parameter estimates. Given these estimates, we solve equation (12) and use the resulting structural errors $\left(\varepsilon^{D}, \varepsilon^{S}\right)$ to update the weight matrix.

${ }^{26}$ As heavier cars contain more steel, we multiply WEIGHT by SPI and recompute HPW. 
Parameter Identification and Instruments. The parameter estimates are pinned down in the GMM estimation via the instruments $H$. The intuition into how data variation identifies different components of $\theta$ is as follows. Mean utility parameters $\beta$ and cost parameters $\gamma$ are recovered using the linear projection outlined in Nevo (2000) using equations (10) and (11). Consequently, the mean utility vector $\beta$ is identified by correlations between market shares and observable product characteristics after controlling for persistent variation in brand (via $F$ ), segment (via $S$ ), and model (via $\rho_{\xi}$ ). The identification of $\gamma$ follows from variation in observable product characteristics and implied marginal costs where the latter depends on variation in price and market shares via the price coefficient $\alpha$, plus the shocks to fuel price and steel prices. Given the exogeneity of product set, the components of $X$ and $Z$ are sufficient instruments for $\beta$ and $\gamma$.

\section{Figure 4: Sample Variation of Household Income}

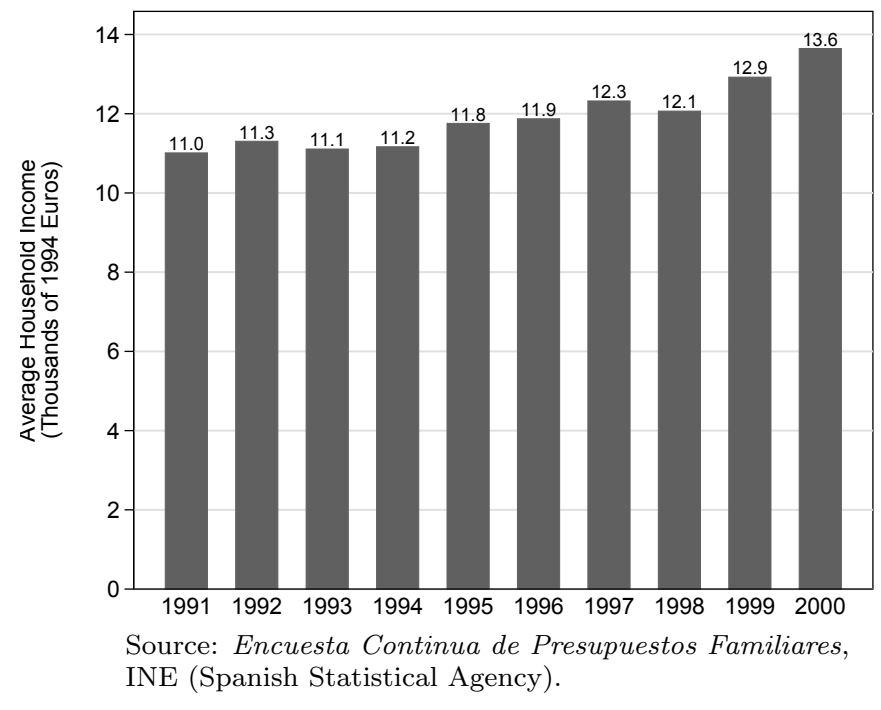

The timing of unobserved quality shocks $\nu$ makes past product characteristics valid instruments to identify the $\operatorname{AR}(1)$ persistence term $\rho_{\xi}$ and therefore, this parameter is identified by persistence in market shares not explained a general time TREND, or a specific fuel time effect, DIESEL $\times$ TREND. The price coefficient $\alpha$ is identified by changes in the income distribution over the economic cycle of Figure 4 plus variation in prices and quantity sold over the sample period. We instrument for price using the total number of products accounting for differences in firm portfolios. This provides two instruments: (1) the sum of other products in the firm's period $t$ portfolio and (2) the number of products produced by other firms in period $t$. Reynaert and Verboven (2014) show that including the supply-side pricing decision aids in the identification of $\alpha$. Residuals from the GMM estimation are used to compute $\sigma_{\nu}^{2}$.

The remaining parameters are the random coefficients $\Sigma$ which govern product substitution patterns among observable characteristics. Under the assumption the product set is exogenous, a common assumption, we use variation in the product set to identify these parameters taking advantage of changes in product characteristic space (e.g., HPW, SIZE, KPE) plus changes in prices and quantities to isolate these substitution patterns. 
Our specification includes a CONSTANT and an indicator for DIESEL engines. These parameters govern substitution within the gasoline and diesel segments, respectively. The sum of products in and outside the portfolios of firms not only aid in instrumenting for price, they also provide identification for the CONSTANT random coefficient. We construct the instruments for the DIESEL random coefficient using the number of vehicles within fuel types as in Bresnahan, Stern and Trajtenberg (1997): (1) the sum of other products in the firm's period $t$ portfolio of the same fuel type as product $j$, and (2) the number of products of the same fuel type as product $j$ produced by other firms in period $t$. Thus, the random coefficient for diesel vehicles is identified by the correlation between changes in the number of diesel vehicles in the product set and changes in purchase shares of diesel vehicles. A similar rationale holds for the constant random coefficient with respect to gasoline-powered vehicles.

Other random coefficients (HPW, SIZE, and KPE) refer to continuous characteristics. We construct instruments for these random coefficients by approximating the "optimal instruments" of Chamberlain (1987) using the "differentiation IVs" of Gandhi and Houde (2015). ${ }^{27}$ The idea is to use the distributions of product characteristics to identify $\Sigma$ by constructing cdf's for each continuous characteristic based on the pairwise distances among any two products. For example, we can construct a cdf for a 1995 Audi A4 in KPE space by looking at the distance between that model's fuel economy and the fuel economy of other models in that year. The addition or subtraction of models over time then impacts this distribution. When consumers value fuel economy, orthogonality between $\varepsilon^{d}(\theta)$ and this cdf is achieved by increasing the KPE random coefficient - a similar intuition to the instruments used in $B L P$.

We operationalize this approach by replacing the large-dimensional cdfs with sample statistics. Specifically, the period $t$ instrument for product $j$ and characteristic $k$ is

$$
\begin{aligned}
H_{j t}^{k, 1} & =\sum_{\substack{r \neq j \\
r \in \mathcal{F}_{j}}}^{\mathcal{J}_{t}}\left(d_{r j, t}^{k}\right)^{2} \\
H_{j t}^{k, 2} & =\sum_{\substack{r \neq j \\
r \neq \mathcal{F}_{j}}}^{\mathcal{J}_{t}}\left(d_{r j, t}^{k}\right)^{2} \\
H_{j t}^{k, 3} & =\sum_{r \neq j}^{\mathcal{J}_{t}} d_{r j, t}^{k} \times \mathbf{1}\left(d_{r j, t}^{k}<\operatorname{sd}\left(x_{\cdot, t}^{k}\right)\right) \\
H_{j t}^{k, 4} & =\sum_{\substack{r \neq j \\
r \in \text { Fuel }_{j}}}^{\mathcal{J}_{t}} d_{r j, t}^{k} \times \mathbf{1}\left(d_{r j, t}^{k}<\operatorname{sd}\left(x_{\cdot, t}^{k}\right)\right)
\end{aligned}
$$

where $d_{r j, t}^{k}$ is the distance in product characteristic space $k$ between products $j$ and $r$ defined as $x_{r, t}^{k}-x_{j, t}^{k}$ and $s d\left(x^{k}\right)$ is the standard deviation of characteristic $k$. Thus, $H_{j t}^{k, 1}$ sums the square of

\footnotetext{
${ }^{27}$ Reynaert and Verboven (2014) further discuss instrumentation of discrete choice demand systems.
} 
the distances products of the same brand than product $j ; H_{j t}^{k, 2}$ of products of other brands; $H_{j t}^{k, 3}$ of "close" products of any brand; and $H_{j t}^{k, 4}$ of close products of the same fuel type. We follow a similar approach in constructing the supply-side instruments.

\subsection{Estimation Results}

We present the parameter estimates for a logit model and our preferred the random coefficient logit ("RC Logit") specification in Table 2. Overall, the estimates are reasonable, statistically significant, and congruent with the descriptive evidence of the Spanish automobile industry of Section 2.

Table 2: Demand and Supply Estimates for Different Specifications

\begin{tabular}{|c|c|c|c|c|}
\hline & \multicolumn{2}{|c|}{ Logit } & \multicolumn{2}{|c|}{ RC Logit } \\
\hline & Coefficient & Rob. SE & Coefficient & Rob. SE \\
\hline \multicolumn{5}{|l|}{ Mean Utility $(\beta)$} \\
\hline CONSTANT & -12.8646 & $(0.8857)$ & -19.8474 & $(5.3107)$ \\
\hline HPW & 0.5469 & $(0.0734)$ & -2.3574 & $(1.5000)$ \\
\hline SIZE & 4.3136 & $(0.7028)$ & 6.1807 & $(5.6900)$ \\
\hline KPE & 0.3822 & $(0.0960)$ & 1.0342 & $(0.5598)$ \\
\hline TREND & 0.0589 & $(0.0156)$ & 0.4668 & $(0.1888)$ \\
\hline DIESEL & -1.1659 & $(0.2074)$ & -10.2957 & $(4.8363)$ \\
\hline DIESEL $\times$ TREND & 0.1672 & $(0.0226)$ & 0.6763 & $(0.2644)$ \\
\hline \multicolumn{5}{|l|}{ Standard Dev. $(\sigma)$} \\
\hline CONSTANT & & & 2.9841 & $(2.1617)$ \\
\hline HPW & & & 1.2504 & $(0.5075)$ \\
\hline SIZE & & & 4.2742 & $(2.1363)$ \\
\hline KPE & & & 0.8242 & $(0.3740)$ \\
\hline DIESEL & & & 5.4194 & $(2.8847)$ \\
\hline \multicolumn{5}{|l|}{ Interactions $(\Pi)$} \\
\hline PRICE/INCOME & -1.6853 & $(0.0957)$ & -2.2252 & $(0.0695)$ \\
\hline \multicolumn{5}{|c|}{ Transition Process for Unobserved Quality } \\
\hline$\rho_{\xi}$ & & & 0.8618 & $(0.0087)$ \\
\hline$\sigma_{\nu}^{2}$ & & & 0.8818 & $(0.1481)$ \\
\hline \multicolumn{5}{|l|}{ Cost $(\gamma)$} \\
\hline $\ln (\mathrm{HPW} / \mathrm{SPI})$ & 6.4626 & $(1.1368)$ & 0.7954 & $(0.0478)$ \\
\hline $\ln (\operatorname{SIZE} \times \mathrm{SPI})$ & 20.6792 & $(3.6212)$ & 2.8725 & $(0.1191)$ \\
\hline $\ln (\mathrm{C} 90)$ & -2.3107 & $(1.2663)$ & 0.6027 & $(0.0431)$ \\
\hline TREND & 0.0796 & $(0.0985)$ & -0.0237 & $(0.0029)$ \\
\hline DIESEL & 4.1180 & $(2.0462)$ & 0.4271 & $(0.0342)$ \\
\hline DIESEL $\times$ TREND & -0.3082 & $(0.2623)$ & -0.0057 & $(0.0032)$ \\
\hline
\end{tabular}

Recall that diesel vehicles present two primary differences from gasoline vehicles: better fuel efficiency (measurable) and greater torque at low r.p.m. (unobservable). The former we capture via our measure of fuel economy (KPE) in consumer utility while the latter we capture by 
including diesel dummy and trend variables (DIESEL, DIESEL $\times$ TREND) in mean utility. We find that consumers do indeed value fuel economy $\left(\hat{\beta}_{\mathrm{KPE}}>0\right)$ and the effect is statistically significant. This result identifies the first channel by which the fuel taxation and vehicle emission standards chosen by European regulators implicitly promoted these vehicles. Fuel economy (KPE) accounts for both differences in fuel efficiency (MPG) and fuel price. A low diesel fuel tax therefore increases diesel fuel economy relative to gasoline-powered models and increases both diesel vehicle sales and profits for the auto makers who produce them. Stricter $N O_{x}$ emissions standards require modifications to the engine which add weight and decrease performance, including fuel efficiency. Thus, weak emission standards also increase the attractiveness of diesel vehicles by increasing fuel economy.

At the beginning of the sample consumers value diesels less than gasoline-powered cars $\left(\hat{\beta}_{\text {DIESEL }}<0\right)$ but their perceptions of diesels increase over the decade. The increasing valuation of diesels could reflect improvements to unobserved quality or consumers learning about the next generation diesel technology, the turbodiesel. Unfortunately, our data do not enable us to differentiate between these two hypotheses. We also find persistence in the unobserved quality of automobiles, $\hat{\rho}_{\xi}>0$, even after controlling for differences in brand though temporary demand are also important $\left(\hat{\sigma}_{\nu}^{2}>0\right)$. On the cost side, we find that diesels are more expensive to manufacture than gasoline models. Marginal cost of production are also higher for larger and more powerful cars. Marginal cost is decreasing in fuel efficiency (increasing in c90). Our cost estimates also indicate significant efficiency gains throughout the decade for both gasoline and diesel vehicles.

Our results indicate that small, inexpensive cars tended to have less elastic demand - a result consistent with Grigolon and Verboven (2014, Table 8) for the German automobile industry. For example, the average estimated demand elasticities for COMPACT, SEDAN, and LUXURY vehicles are 2.52, 2.96, and 3.86, respectively. Thus, an automaker tended to generate more profit per vehicle selling a COMPACT car $(44.25 \%$ average estimated price-cost margin) than a LUXURY car ( $28.67 \%$ average estimated price-cost margin). ${ }^{28}$

Significant estimates for the HPW, SIZE, KPE, and DIESEL random coefficients indicate a great deal of heterogeneity among consumers though these estimates are smaller (in absolute value) than the corresponding estimates on the mean utility so both components tend to be important when consumers make purchase decisions. Interestingly, we find the random coefficient for gasoline cars $\left(\hat{\sigma}_{\text {CONSTANT }}\right)$ is large but insignificant indicating that other characteristics account for the majority of the variation in car substitution patterns.

In Figure 5 we show the inclusion of random coefficients translates into reasonable estimated substitution patterns. In panels (a-c) we compare the average cross-price elasticity among products as we increase the product distance, $d_{r j, t}^{k}$, in characteristic space. For each observable product characteristic we divide the product pairs into deciles and plot the average cross-price elasticity on the x-axis. Product pairs in the left-most bins are therefore closer together than product pairs in the right-most bins. Panels (a-c) all indicate that car models close together in characteristic space tend

\footnotetext{
${ }^{28}$ We define the price-cost margin of vehicle $j$ in period $t$ as $100 \times \frac{p_{j t}^{w}-\hat{c}_{j t}}{p_{j t}^{w}}$ where $p_{j t}^{w}$ is the price set by the automaker
} (i.e., does not include any applicable tariff) and $\hat{c}_{j t}$ is the estimated marginal cost of producing vehicle $j$. 
Figure 5: Cross-Price Elasticities

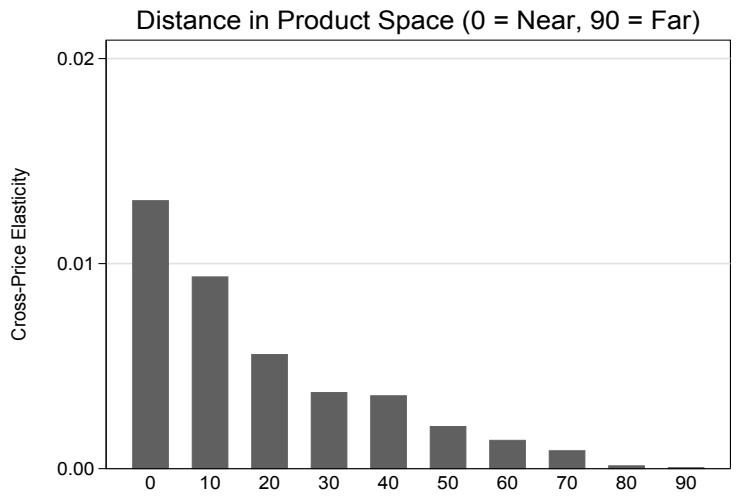

(a) HPW

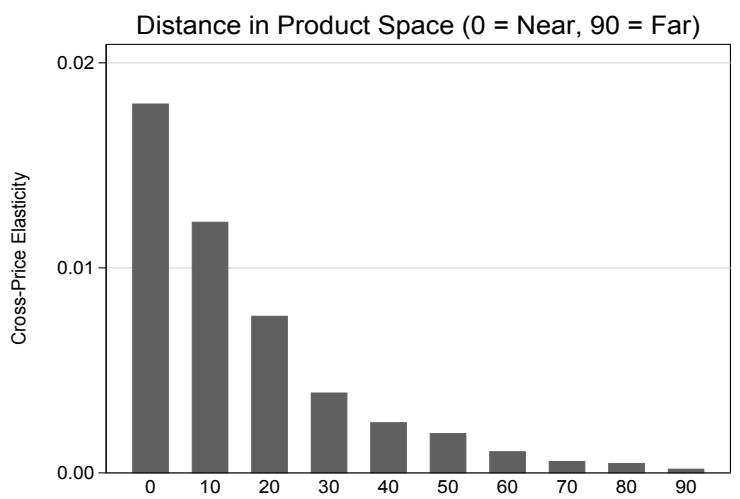

(c) KPE

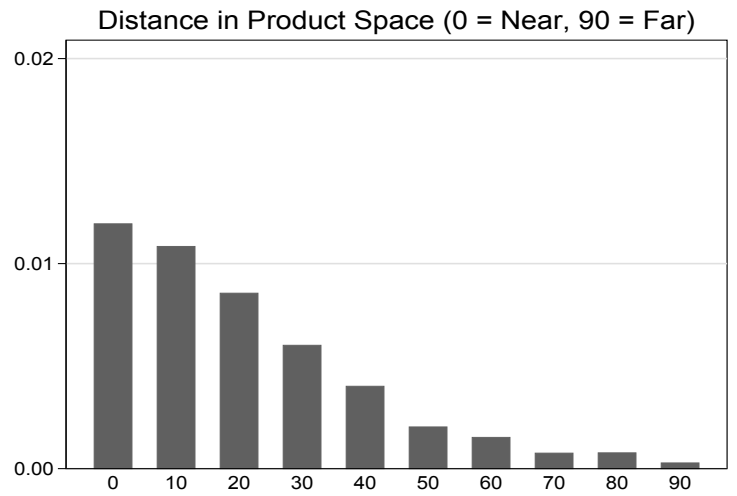

(b) SIZE

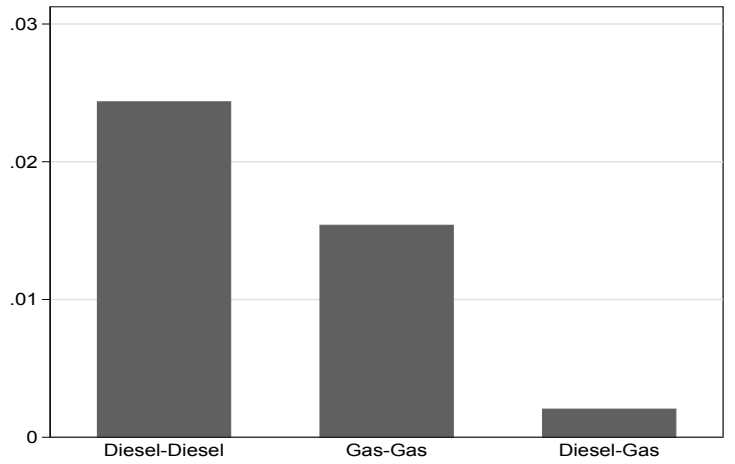

(d) Fuel Type

Notes: Figures present average estimated cross-price elasticities across characteristics (panels a-c) and engine-type (panel d). In Table E.1 we present the matrix of estimated cross-price elasticities for the most popular products while in Table E.2 we present the "best substitute" for a select number of products.

to be better substitutes. Since diesel is a discrete variable, we show the average cross-price elasticity within and across fuel types (panel d). Our estimates indicate that diesels are closer substitutes to other diesels and that gasoline models are closer substitutes to other gasoline models.

In Figure E.1 we report our estimates of the brand fixed effects in demand and supply relative to the Spanish market leader, REnAult. Again, results are very reasonable. German upscale brands AUDI, BMW, and MERCEDES have higher valuations but are also the most expensive to produce. Foreign imports tend to be relatively inexpensive to produce (e.g., DAEWOO, HYUNDAI, KIA) although less so among those with higher estimated valuations among consumers (e.g., HONDA and тоуота). Meanwhile the old Spanish brand SEAT, now operated by VOLKSWAGEN, is both inexpensive to produce and relatively well valued by consumers, though both effects are small.

In Figure 6 we demonstrate the importance of the transitory demand shocks captured by $\hat{\nu}$ towards predicting consumer demand. We do so by comparing the actual vehicle market shares (y-axis) to the predicted market shares when we set $\nu=0$ (x-axis). As the model generates observed demand by construction, if setting transitory demand shocks played little role setting $\nu=0$ would 
correspond to only small deviations in predicted demand. Graphically, this would correspond to points concentrated on the dashed 45-degree line of Figure 6. While there is some bunching around the 45-degree line reflecting the importance of other demand-side covariates, we also observe large deviations indicating that transitory demand shocks are also important.

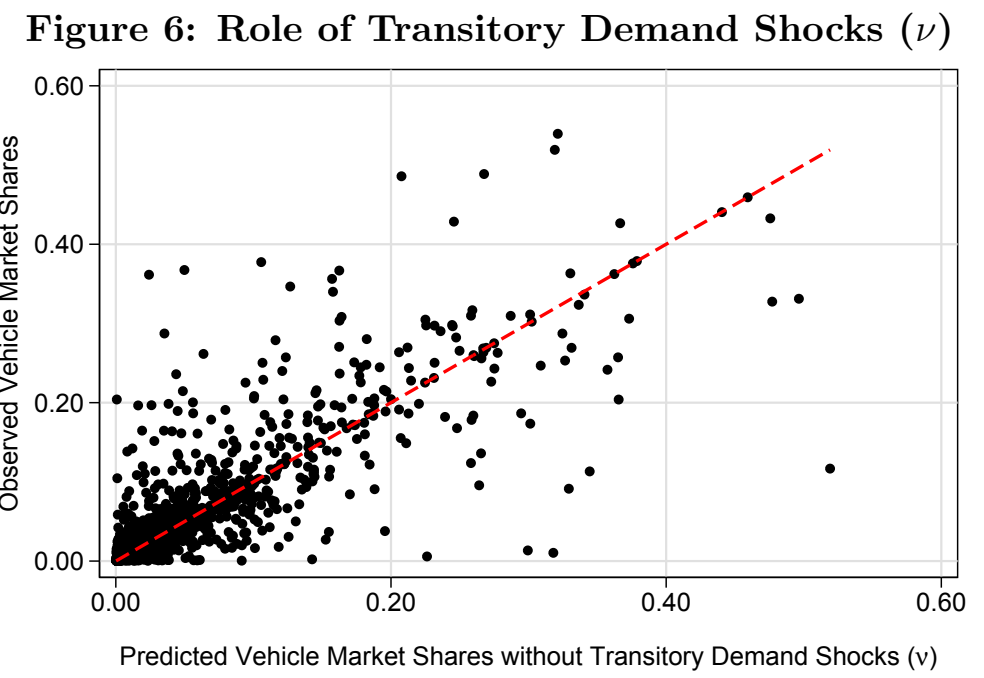

Notes: Figure compares the actual vehicle market shares (y-axis) to the predicted market shares under the restriction of $\nu=0$ (x-axis).

In Table 2 we also compare our preferred RC Logit estimation to that of a simple multinomial logit model where the latter differs from the RC Logit model in two ways. First, it restricts substitution patterns by imposing $\Sigma=0$ and $y_{i, t}=\overline{y_{i t}}$. Second, we assume no autocorrelation in unobserved characteristic and impose $\rho_{\xi}=0, \sigma_{\nu}^{2}=0$. This restricted simple logit model still delivers many of the qualitative results from the estimated RC Logit model, e.g., consumers favor fuel economy (KPE) and have a negative preference for diesels which improves over time. This provides further evidence that pro-diesel fuel taxation and vehicle emission standards promoted diesels by increasing their fuel economy. The most notable difference between the models corresponds to price responsiveness of consumers where in our preferred RC Logit framework consumers are more sensitive to price than in the logit model. We therefore estimate demand to be less elastic in the logit model where $3 \%$ of car models have inelastic estimated demands. In comparison, demand estimates in the RC Logit model yield vehicle demand curves which are always elastic. ${ }^{29}$

In summary, the estimated RC Logit model generates reasonable estimates of consumer demand and supplier marginal cost. The estimated model also delivers reasonable substitution patterns between products (Figure 5) and own price elasticities. We find that consumers value fuel economy (KPE) when purchasing a new vehicle. As the fuel taxation and vehicle emission policies we discussed in Section 3 both increase fuel economy for diesel cars, these estimation results support our hypothesis that these policies promoted diesel vehicles.

\footnotetext{
${ }^{29}$ Although ignoring the distinction between diesel and gasoline models, Moral and Jaumandreu (2007) find similar demand elasticities as our preferred RC Logit estimated model.
} 


\section{Figure 7: Share of Profits from Diesel Cars}

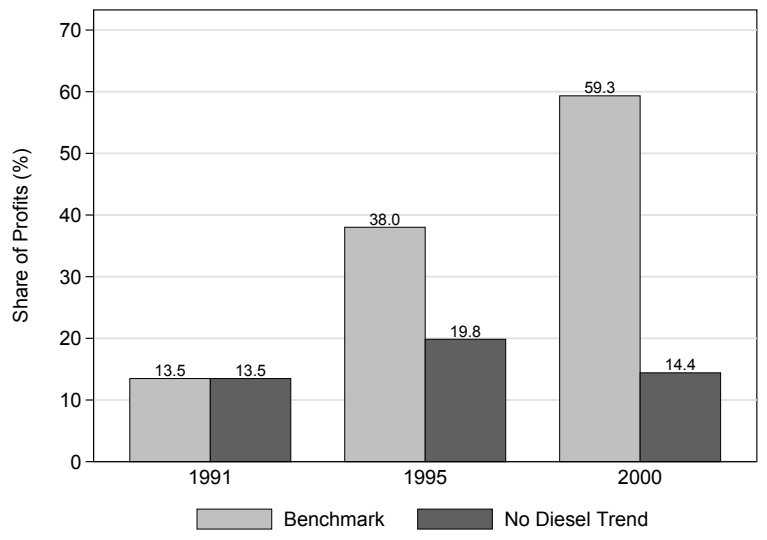

(a) European Firms

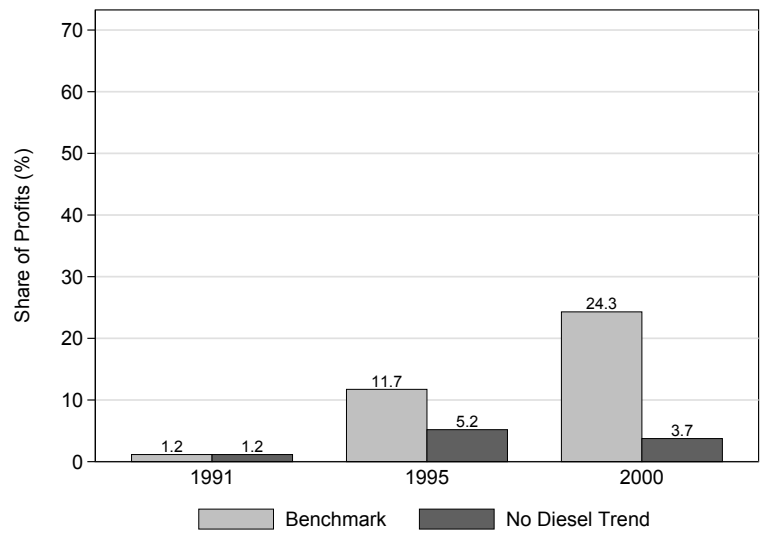

(b) Non-European Firms

Value of Diesels. Before moving on to testing our hypotheses as to whether preferential fuel taxation and vehicle emissions promoted diesels and in so doing amounted to a successful strategic trade policy, we use the parameter estimates to document that diesel cars were indeed a valuable innovation for European firms. In Figure 7 we use our cost estimates to show that diesels generated a significant share of the profits for European firms that increased over time. While profits from diesels also increased for Non-European (largely Asian) firms, their contribution to profits was substantially smaller. If we hold the consumer valuation of diesels fixed at their 1991 level by setting $\beta_{\text {Diesel-x-Trend }}=0$, the importance of diesels to these firms' decreases significantly indicating that the improving valuation of diesels played an important role in the technology's success.

\section{Fuel Taxation and Emissions Policies as Strategic Trade Policy}

In this section we use the estimated RC Logit model to test the quantitative importance of pro-diesel fuel taxation and emissions policy. While there are many potential alternative policies we could consider, we restrict our attention to the following scenarios. We assume European regulators equalize fuel taxes by setting a uniform fuel tax equal to the gas tax we observe in the data. Regarding alternative emissions policies we allow for the possibility that a stricter $N O_{x}$ vehicle emissions policy could affect both the marginal cost of producing diesels and their performance. For simplicity we assume that all diesel models require the same "abatement cost" and suffer the same reduced performance though it is likely these effects would vary by engine and car size.

The task then is to identify a "realistic" cost and change in performance an automaker's diesel fleet would incur to meet the hypothetical stricter $N O_{x}$ emission standard. For years, a technology to successfully capture $N O_{x}$ emissions at the tailpipe simply did not exist. When it finally became available, in the late 2000s, it was still very expensive. By the EPA's own estimates in 2010, diesel engines could be retrofitted to comply with both EPA and California $N O_{x}$ emission standards by means of a Lean $N O_{x}$ Catalyst at an estimated cost of between $\$ 6,500$ to $\$ 10,000$ per vehicle. Lean $N O_{x}$ catalysts use diesel fuel injected into the exhaust stream to create a catalytic 
reaction and reduce pollution. However, these catalysts still require specific exhaust temperatures for appropriate $N O_{x}$ emission control performance, and on average they reduce emissions up to a maximum of $40 \%$. German manufacturers BMW and MERCEDES were certified to be sold in all 50 states of the U.S. in 2009 only after equipping their new vehicles with the more efficient and expensive Selective Catalytic Reduction System that injects a reluctant (a urea-based solution) into the exhaust stream where it reacts with a catalyst to convert $N O_{x}$ emissions to nitrogen gas and oxygen. This system is more effective, reducing $N O_{x}$ emissions up to $75 \%$ but the EPA estimated that its retrofitting cost ranged between $\$ 10,000$ and $\$ 20,000$ per vehicle in $2010 .{ }^{30}$

These options for abatement technology yields a great deal of variation for how European automakers may have responded to a more rigorous $N O_{x}$ vehicle emissions standards. If we assume such a technology did in fact exist in the 1990s, the abatement cost estimates from EPA are likely biased-upwards as they amount estimated costs for the ex post retrofitting of vehicles to meet the stricter American emission standard. It seems likely that an auto maker making an ex ante modification to a diesel vehicle could likely do so at a lower cost. We therefore model two scenarios at different estimates of abatement cost in hopes of providing a reasonable range for the likely impact of a stricter $N O_{x}$ emission policy. First, we assume the marginal cost of attaching an abatement system (either LNC or SCR) to a 1990s European diesel would have been the lower bound of the above ex post retrofitting estimates $(\$ 6,500) .{ }^{31}$ We view this estimate change in marginal cost as a likely upper bound and refer to this scenario as "EPA." Second, we consider the "NONE" scenario where meeting a stricter $N O_{x}$ standard does not impact the marginal cost of diesels at all. We view this scenario as a lower bound since adding abatement technology at the very least requires the purchase and installation of a SCR or LNC system.

To evaluate the impact of stricter emissions policies on performance, we use the 2015 Volkswagen emissions scandal as guidance as these vehicles were equipped with viable SCR abatement systems so the company had incurred the increased marginal cost to include the abatement technology. The scandal therefore highlighted the impact of a stricter $N O_{x}$ vehicle emissions on engine performance as the company included a software-based "defeat device" which changed how the vehicle used the SCR system:

The software sensed when the car was being tested and then activated equipment that reduced emissions, United States officials said. But the software turned the equipment down during regular driving, increasing emissions far above legal limits, most likely to save fuel or to improve the cars torque and acceleration. ${ }^{32}$

The fact that Volkswagen management was willing to risk billions of dollars in fines and damage to the brand's value for the sake of increasing performance (e.g., fuel efficiency) speaks to

\footnotetext{
${ }^{30}$ On abatement costs see Diesel Retrofit Devices. EPA's National Clean Diesel Campaign, 2013. http://www.epa. gov/cleandiesel/technologies/retrofits.htm as well as our summary in Appendix C.

${ }^{31}$ In 1994 euros this figure amounts to an increase in marginal cost of $€ 3,300$ or $23.9 \%$ of the average (sales-weighted) diesel retail price of $€ 13,794$ in our sample.

32 "How Volkswagens 'Defeat Devices' Worked." New York Times. March 16, 2017.
} 
the importance of this channel towards selling diesel vehicles. The question then is: How big is this change in performance? For the emissions scandal, evidence suggests that the modifications required to bring diesels in compliance with the U.S. $N O_{x}$ standard decreases fuel efficiency (MPG) $6.8 \%$ on average. We therefore assume that under both the "None" and "EPA" cost scenarios described above, meeting the stricter $N O_{x}$ emission standard we consider decreases fuel efficiency (MPG) $6.8 \%$ and thereby decreases fuel economy (KPE). We view this as a likely lower bound on the impact to performance since part of the benefit of diesels is also the (unobservable to us) increased torque at low r.p.m. which is captured only in the diesel fixed effect and diesel-trend variable.

\subsection{The Shrinking Popularity of Diesels Under Alternative Policies}

We begin the analysis by evaluating how fuel taxation and emission standards affect the demand for diesel automobiles. In Figure 8 we use the estimated model to show that switching to a less diesel-friendly fuel tax or a more $N O_{x}$ stringent vehicle emission standard leads to significant reductions in the popularity of diesels across the entire sample.

Figure 8: Fuel Economy, Fuel Efficiency and Diesel Popularity

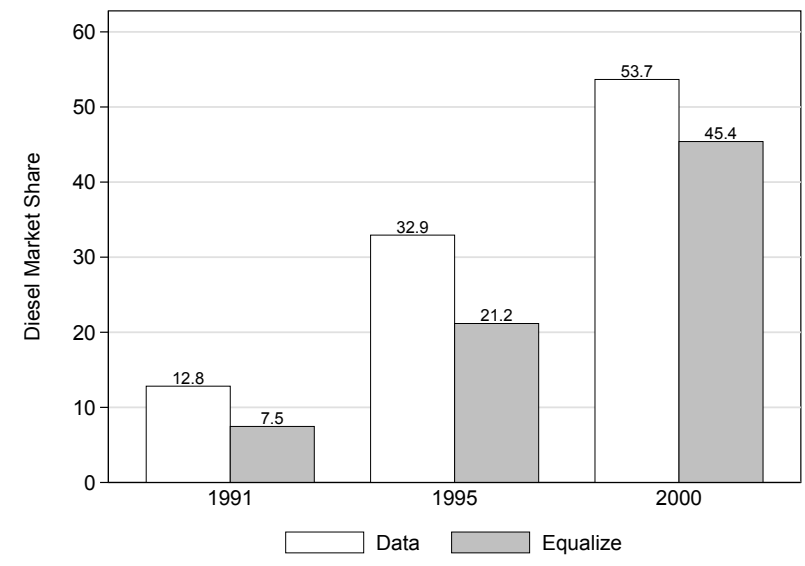

(a) Fuel Tax

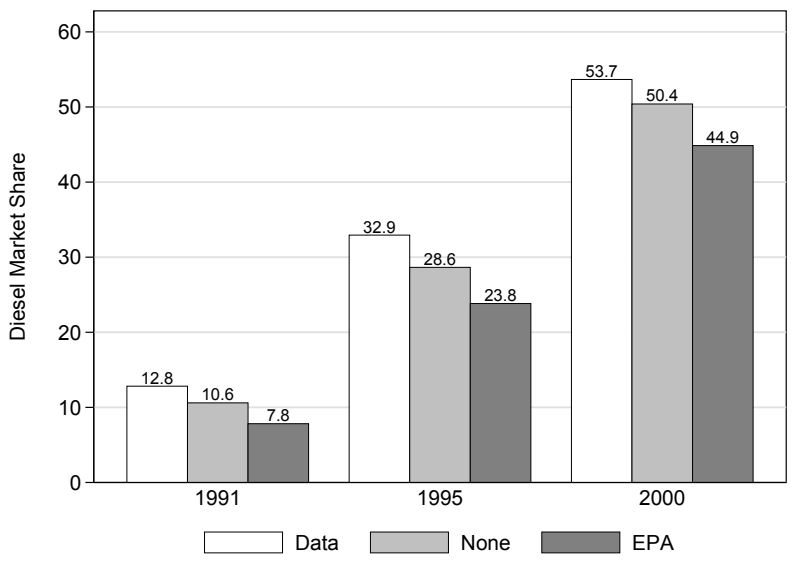

(b) Vehicle Emissions

Notes: Bars reflect market share of diesels as a function of different fuel tax and vehicle emission policies.

In panel (a), we show that modifications to the fuel tax impacts the relative gasoline/diesel fuel prices facing consumers and ultimately leads to a reduction in diesel sales. The uniform fuel tax scenario where all fuels are taxed at the current higher gasoline tax increases the driving costs of diesel vehicles and results in sizable reductions in diesel market share: $\downarrow 5.3 \%, \downarrow 11.7 \%$, and $\downarrow 8.3 \%$ in 1991, 1995, and 2000, respectively. These results are in-line with Grigolon, Reynaert and Verboven (2017, Table 7) who predict that the 1998 diesel market share in Spain would have decreased $9 \%$ had regulators increased the diesel fuel tax such that the price of diesel fuel matched the price of gasoline. ${ }^{33}$

\footnotetext{
${ }^{33}$ In contrast we allow for the cost of gasoline and diesel fuel to differ and instead equalize the fuel taxes leading to a higher price of diesel fuel relative to gasoline (Figure 2).
} 
Figure 9: Which Firms Benefit from Current Policy?

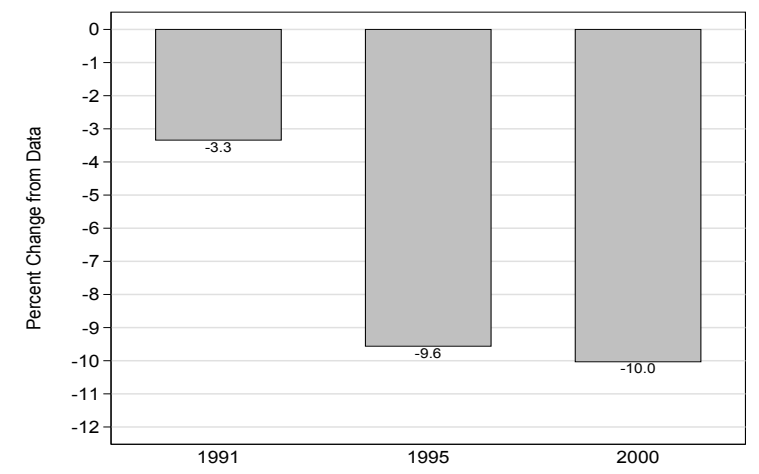

(a) European Firm Profits (Fuel Tax)

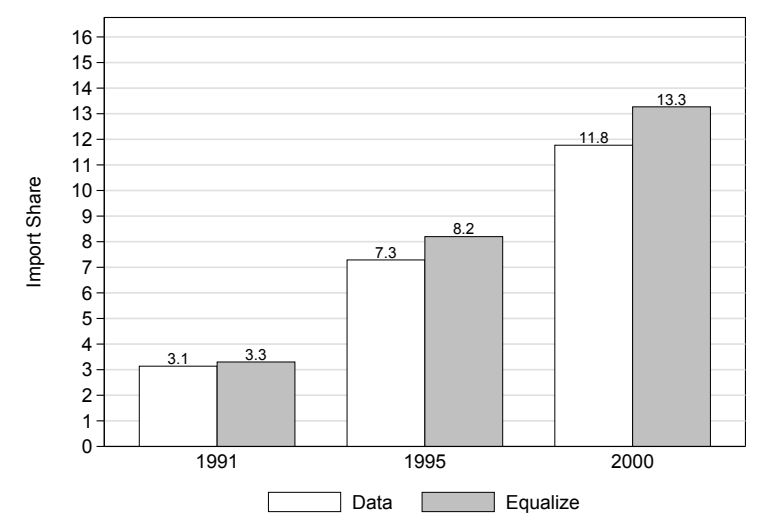

(c) Import Share (Fuel Tax)

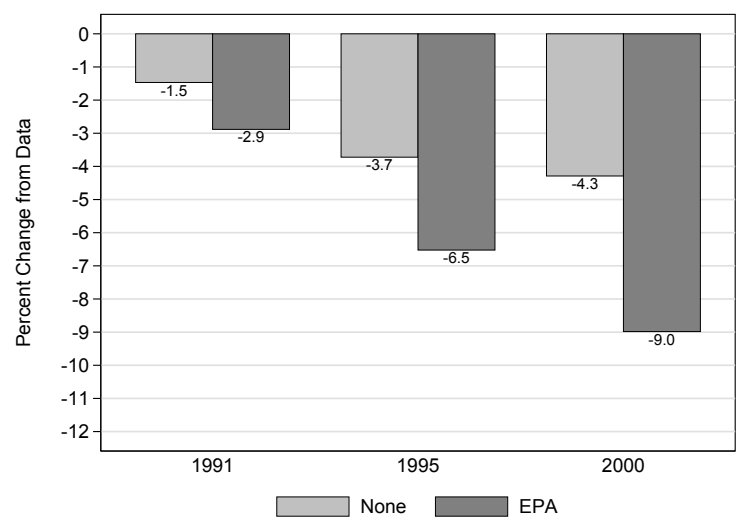

(b) European Firm Profits (Vehicle Emissions)

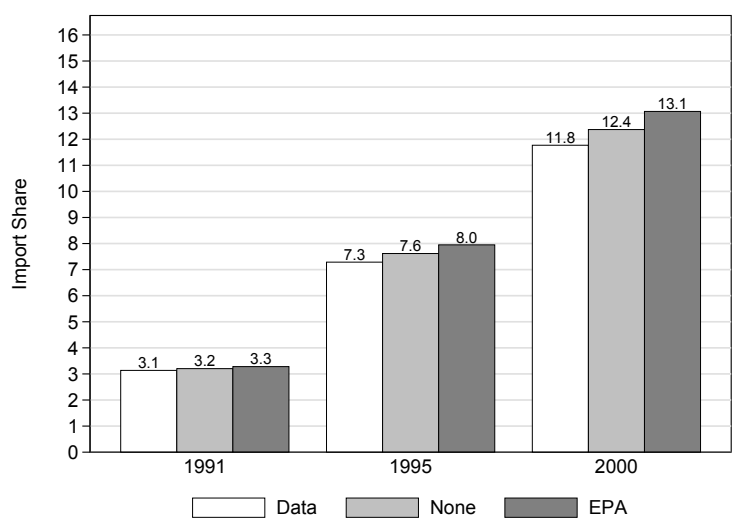

(d) Import Share (Vehicle Emissions)

Notes: Panels (a)-(b) present change in total profit for aggregate profits for European firms. Panels (c)-(d) reflect total import share across time under different policies. "Data" corresponds to the import share observed in the data. Cuonterfactual experiments are described in the text. We present the cumulative effects of both policies to European firm profits and import share in Figure E.2.

Panel (b) shows smaller but qualitatively similar effects due to a stricter $N O_{x}$ vehicle emissions policy. We begin by looking at the impact of such a standard when we assume automakers could have met the stricter standard by modifying performance alone (i.e., "None"). Under this scenario, diesel market share falls $2.2 \%$ in 1991 and $3.3 \%$ in 2000 . When we also account for the increased cost from attaching an abatement technology to the engine (i.e., "EPA") firms optimally choose to pass through some of this expense to consumers leading to higher diesel vehicle prices and even lower penetration of diesel vehicles: decreasing $5.0 \%$ in 1991 and $8.8 \%$ in 2000 .

In Figure 9 we evaluate financial implications of these policies to firms in order to identify the beneficiaries of the observed pro-diesel policies. We focus on the share of imports and the profits of European manufacturers to highlight how these pro-diesel policies soften competition by directing demand away from gasoline imports towards diesel-powered domestic automobiles. From panels (a) and (b) we see that instituting the alternative policies we consider decreases profits for European firms significantly while import shares increase (panels c-d) as consumers substitute away from domestic diesels and towards foreign (largely Asian) gasoline-powered vehicles. Put 
differently, Figure 9 demonstrates that European firms benefited significantly from both of the pro-diesel policies employed by regulators. Moreover, these effects increased over time as domestic automakers invested in developing their diesel fleets (i.e., Table 1).

\subsection{Import Tariff Equivalence}

Thus far we have shown that diesel vehicles were a popular choice among consumers and generated substantial profits for European automakers, but much of this success was due to preferential fuel taxes and vehicle emissions standards which shifted consumption and profits towards domestic firms. In this section we use the model estimates to measure the tariff equivalence of these policies. We do this in the following way. First, we solve for the pricing equilibrium when European regulators choose the alternative policies we consider. Under this equilibrium we observe substitution towards imported varieties Figure 9, panels (c-d). We then solve for the import tariff each year which reduces equilibrium import share to the level we observe in the data, i.e., incentivizes consumers to purchase local vehicles. We call this value the "import tariff equivalence" of the policies.

Table 3: Implicit Tariff by Year Across Policies

\begin{tabular}{lcccc}
\hline \hline YEAR & OFFICIAL & FUEL TAX & EMISSIONS & BOTH \\
\hline 1991 & 18.80 & 21.72 & 21.38 & 23.22 \\
1992 & 14.40 & 18.27 & 17.69 & 20.01 \\
1993 & 10.30 & 14.96 & 14.09 & 17.12 \\
1994 & 10.30 & 16.11 & 14.60 & 18.54 \\
1995 & 10.30 & 17.67 & 15.60 & 20.55 \\
1996 & 10.30 & 16.64 & 15.12 & 19.86 \\
1997 & 10.30 & 18.07 & 15.94 & 22.03 \\
1998 & 10.30 & 18.94 & 15.92 & 22.81 \\
1999 & 10.30 & 21.69 & 17.91 & 27.36 \\
2000 & 10.30 & 19.65 & 17.81 & 25.28 \\
\hline
\end{tabular}

Notes: "Data" is the current import tariff on foreign imports. "Fuel Tax" corresponds to the implicit import tariff for the observed fuel excise taxes. "Emissions" corresponds to the implicit tariff for the observed emissions policy under the assumption that the stricter $N O_{x}$ policy requires a $€ 3,300$ increase in marginal cost ("EPA") and a $6.8 \%$ reduction in fuel efficiency for all diesels. "Both" corresponds to the implicit tariff when both policies are enforced simultaneously.

In Table 3 we present the import tariff equivalence of the pro-diesel policies employed by the European Union. In the right-most column we present the tariff required to maintain import market share observed in the data when regulators equalize fuel taxes and impose vehicle emission standards which increase diesel marginal costs and decrease fuel efficiency $6.8 \%$ (i.e., "EPA"). ${ }^{34}$ Recall that fuel economy (KPE) is defined as

$$
\mathrm{KPE}=\frac{\text { "Fuel Efficiency" }}{\text { "Fuel Price" }}
$$

\footnotetext{
${ }^{34}$ Table E.3 further details the tariff-equivalence across vehicle emissions assumptions.
} 
Therefore, a $6.8 \%$ reduction in fuel efficiency (MPG) due to stricter fuel emission standards also amounts to a $6.8 \%$ reduction in fuel economy (KPE). An increase in the diesel fuel excise tax to match the higher gasoline excise tax impacts KPE differently, however, as such a tax change increases the diesel "Fuel Price" leading to a reduction in diesel KPE. In our data equalizing fuel taxes alone amounts to a $16.8 \%$ decrease in diesel KPE in 2000. If both policies, emissions and fuel taxation, are implemented simultaneously in that year, the two effects compound and diesel fuel economy (KPE) decreases $22.5 \%$.

We find the implicit tariff from these policies ranges from $17.12 \%$ in 1993 to $27.36 \%$ in 1999. Thus, the cumulative impact of these policies amounted to a significant trade policy barrier equivalent to imposing a tariff roughly two to three times the official rate (second column). In the third and fourth columns we isolate the yearly contribution of each policy. To do so, we follow a similar approach to the one outlined above but only change one policy at a time. We find that both policies played important roles and amounted to quantitatively significant de facto non-tariff trade policies during the 1990s though fuel taxes played an increasing role as the decade progressed.

Figure 10: Tariff Equivalence of E.U. Policy

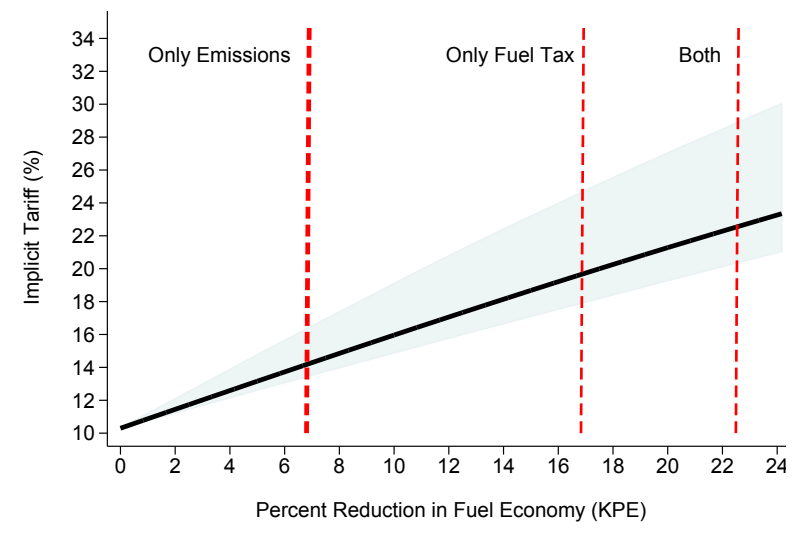

(a) No Change in Marginal Cost ("None")

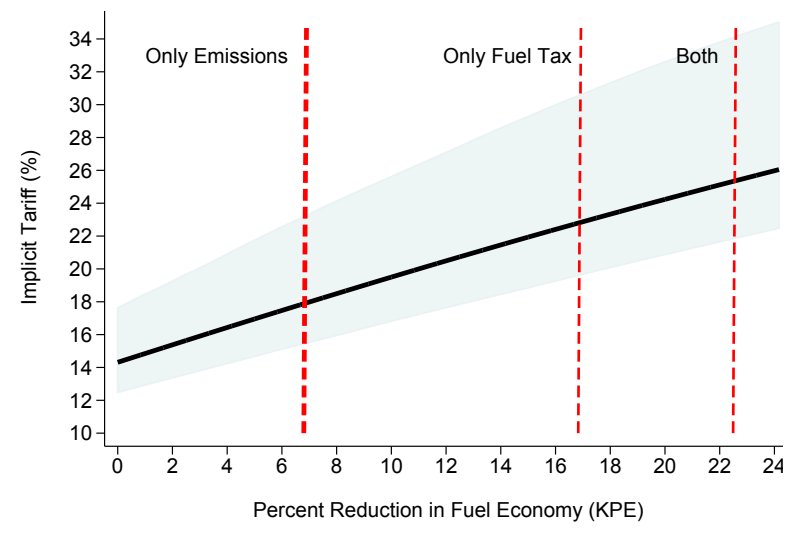

(b) €3,300 Increase in Marginal Cost ("EPA")

Notes: Implicit tariff required to limit the import share to $11.8 \%$ as we decrease fuel economy (KPE) do to changes in fuel taxation and vehicle emission policies. In Panel (a) we consider the case where a stricter $N O_{x}$ vehicle emissions policy has no effect on the marginal cost of producing diesels (i.e., "None" in the text) whereas in Panel (b) we assume the cost of producing diesels increases $€ 3,300$. Vertical dashed lines correspond to estimated changes in fuel economy based on stricter vehicle emissions policy (KPE $\downarrow 6.8 \%$ ), equalized fuel taxes (KPE $\downarrow 16.8 \%$ ), or both (KPE $\downarrow 22.5 \%$ ). Shaded areas correspond to the $95 \%$ confidence interval. See Appendix D computational details. Results correspond to year 2000 when the official import tariff was $10.3 \%$.

Our calculation of the import tariff equivalence of EU policy depended upon these policies' effect on diesel popularity via improved fuel economy (KPE) as well as changes in marginal cost to meet more rigorous $N O_{x}$ vehicle emission standards. In Figure 10 we document that each of these channels played a significant role in defending domestic industry. We do so by plotting the import tariff in 2000 required to generate the import share we observe in the data, about $11.8 \%$ in 2000 , across different changes in fuel economy (x-axis). In panel (a) we present the case where more a rigorous $N O_{x}$ vehicle emission policy does not impact the marginal cost of producing diesel vehicles while in panel (b) we present the "EPA" scenario where these alternative standards increase the 
marginal cost of producing diesel vehicles $€ 3,300$. Thus, a zero percent change in KPE when the alternative vehicle emission policy does not impact marginal costs amounts to the equilibrium we observe in the data and the tariff is simply the official import tariff of 10.3 percent. Graphically, this scenario is represented by the y-intercept in panel (a). The vertical dashed lines in each panel correspond to the change in fuel economy implied by removing the the pro-diesel policies. Thus, the intersection of the dashed lines with the solid line in panel (b) corresponds to the implicit tariffs

we presented in Table 3 for 2000. Shaded regions indicate the 95 percent confidence intervals of the estimated implicit tariff. Inference is based on bootstrapping simulations using the demand and cost estimates from Table 2. See Appendix D for details.

In both panels we find an implicit tariff which is statistically greater than the official $10.3 \%$ rate for all reductions in fuel economy. Moreover, we again find that both the fuel taxation and vehicle emission policies employed by European regulators amounted to large and statisticallysignificant non-trade policies and that together these effects compound. If we focus only on panel (a) and ignore the possibility that changes in policy would have likely impacted vehicle production costs, we find that reductions in the fuel economy of diesel vehicles alone played a large and statistically-significant role in promoting domestic industry. As both preferential fuel taxes and a weak $N O_{x}$ emission standard increased the fuel economy of diesel vehicles, panel (a) demonstrates that these policies promoted diesel vehicles by increasing their fuel economy absent changes in the marginal of producing diesels

In panel (b) we redo the analysis assuming a more rigorous $N O_{x}$ vehicle emission standard would have increased the marginal cost of producing diesel vehicles by $€ 3,300$. We observe an upward shift in the line relative to panel (a) indicating that increasing the marginal cost of producing diesel vehicles leads to higher equilibrium prices causing consumers to shift consumption from domestic diesels towards foreign gasoline-powered imports. For example, if we ignore the role of changes in fuel economy due to changes in policy (set $\Delta$ KPE to zero), we find that changes in diesel marginal cost would have generated sufficient substitution towards foreign imports that only by increasing the import tariff from $10.3 \%$ to $14.4 \%$ (i.e., the solid line's y-intercept) could EU regulators have maintained data import share at $11.8 \%$. We conclude that a weak $N O_{x}$ emission policy promoted diesels by also decreasing their production costs leading to lower prices for pricesensitive consumers.

\subsection{Consumer Welfare}

Thus far our analysis has focused on the impact of pro-diesel regulations on market shares of imported automobiles in Europe and on the increased profits of domestic auto makers. In this section we evaluate the impact of these policies to consumer welfare which we define as mean compensating variation, i.e., the average amount of money required to make consumers indifferent when we institute alternative fuel tax and vehicle emission policies and recompute the equilibrium. As our demand model allows for income effects, we solve for compensating variation accounting 
Table 4: Government Policy and Consumer Welfare

\begin{tabular}{|c|c|c|c|c|c|c|c|c|}
\hline \multirow{3}{*}{$\frac{\text { YEAR }}{1991}$} & \multicolumn{4}{|c|}{ ALTERNATIVE POLICIES } & \multicolumn{4}{|c|}{ ALTERNATIVE POLICIES + TARIFF } \\
\hline & \multicolumn{2}{|c|}{ NONE } & \multicolumn{2}{|c|}{ EPA } & \multicolumn{2}{|c|}{ NONE } & \multicolumn{2}{|c|}{ EPA } \\
\hline & $€ 28.74$ & $(0.21 \%)$ & $€ 72.51$ & $(0.54 \%)$ & $€ 267.57$ & $(1.99 \%)$ & $€ 519.15$ & $(3.85 \%)$ \\
\hline 1992 & 43.91 & $(0.32 \%)$ & 124.65 & $(0.91 \%)$ & 327.16 & $(2.38 \%)$ & 635.56 & $(4.62 \%)$ \\
\hline 1993 & 73.86 & $(0.50 \%)$ & 192.62 & $(1.30 \%)$ & 344.45 & $(2.32 \%)$ & 698.84 & $(4.70 \%)$ \\
\hline 1994 & 113.15 & $(0.69 \%)$ & 277.18 & $(1.68 \%)$ & 558.36 & $(3.39 \%)$ & $1,036.62$ & $(6.29 \%)$ \\
\hline 1995 & 157.31 & $(0.91 \%)$ & 399.56 & $(2.31 \%)$ & 747.87 & $(4.32 \%)$ & $1,359.47$ & $(7.86 \%)$ \\
\hline 1996 & 183.67 & $(1.03 \%)$ & 484.19 & $(2.71 \%)$ & 555.44 & $(3.11 \%)$ & $1,102.95$ & $(6.17 \%)$ \\
\hline 1997 & 233.00 & $(1.32 \%)$ & 609.96 & $(3.46 \%)$ & 643.97 & $(3.66 \%)$ & $1,259.29$ & $(7.15 \%)$ \\
\hline 1998 & 313.26 & $(1.80 \%)$ & 816.54 & $(4.69 \%)$ & $1,836.33$ & $(10.55 \%)$ & $2,991.68$ & $(17.18 \%)$ \\
\hline 1999 & 417.43 & $(2.40 \%)$ & $1,048.13$ & $(6.03 \%)$ & $1,011.58$ & $(5.82 \%)$ & $1,957.05$ & $(11.25 \%)$ \\
\hline 2000 & 402.24 & $(2.26 \%)$ & $1,135.93$ & $(6.38 \%)$ & $1,238.16$ & $(6.95 \%)$ & $2,424.79$ & $(13.61 \%)$ \\
\hline Average & $€ 196.66$ & $(1.14 \%)$ & $€ 516.13$ & $(3.00 \%)$ & $€ 772.39$ & $(4.45 \%)$ & $€ 1,419.45$ & $(8.27 \%)$ \\
\hline
\end{tabular}

Notes: Table depicts mean compensating variation measured in 1994 euros under different abatement cost assumptions where a positive value indicates the average consumer is better-off under the observed pro-diesel policies. Values in parentheses correspond to mean compensating variation as a percent of median retail price in the data. Compensating variation in "Alternative Policies + Tariff" also includes lump sum payment for increased tariff revenue.

for both income and substitution effects following Dagsvik and Karlström (2005). A positive value indicates that consumers would be willing to pay the government to stay in the estimated equilibrium, i.e., they prefer the fuel taxation and vehicle emission policy we observe.

In Table 4 we present the welfare effects to consumers of pro-diesel policy relative to two policy regimes. In the columns marked "Alternative Policies" we compare the current pro-diesel policy to a regime where policymakers both harmonize fuel taxes and introduce a stricter $N O_{x}$ emissions standard which reduces fuel efficiency $6.8 \%$. These columns therefore refer to the consumer welfare effects in Section 6.1 where we documented that these hypothetical fuel taxation and vehicle emission policies cause consumers to switch from diesels and towards imported cars.

Our conclusion is that the average European consumer is better-off each year under the current policies. This is not surprising since the alternative policies we consider both decrease fuel economy (due to higher diesel fuel taxes and a reduction in diesel fuel efficiency) and may increase the retail price of diesels (due to "EPA" abatement costs). These negative welfare effects grow over time as diesels become increasingly popular. In terms of relative magnitudes the change in welfare amounts to $1.14 \%$ of median retail price on average when cost of modifying diesel engines are nil, though the relative impact is nearly double at the end of the decade when diesels are clearly dominant in several automobile segments. If meeting the alternative emissions standards requires positive abatement costs (column "EPA") automakers will pass some of this increase in marginal costs of producing diesels to consumers. Consequently, adopting these alternative polices decreases consumer surplus further and drivers will be even better off under the current pro-diesel policy, about $3 \%$ of median retail price on average though again the effect grows over the decade to over double that gain. Put differently, the benefits of not adopting these alternative policies to consumers increase by a factor of three when we also account for changes in marginal cost. 
In Section 6.2 we calculated the tariff-equivalence of the observed pro-diesel policies. One could interpret this equilibrium as the consequence of a regulator uses only tariffs to manage imports. In "Alternative Policies + Tariff" we evaluate the consumer welfare effects of this policy. For simplicity we assume that incremental tariff revenue is returned to consumers as a lump sum payment. Now the impact to consumer welfare is more severe as regulation not only limits the popularity of diesel cars but also increase the retail prices of foreign imports.

Measuring the full effect to consumers requires accounting for negative health externalities due to greater $\mathrm{NO}_{x}$ but reduced $\mathrm{CO}_{2}$ emissions. If these externalities are large then providing incentives to purchase diesel vehicles may adversely affect consumers and reverse the conclusions from Table $4 .^{35}$ This is particularly true for $N O_{x}$ emissions since externalities such as smog tend to affect local populations. If we assume that regulators are not captured by domestic industry and that they do consider both the externality and consumer welfare when instituting policy, the fact we observe these pro-diesel policies supports the idea that these policies do serve a legitimate purpose: to promote a new technology, the turbodiesel, which turned out to be popular among domestic consumers and happened to be produced by domestic firms. The impact of these policies on foreign firms - their tariff-equivalence - would therefore amount to an unintended consequence.

In summary, we have shown that the European fuel taxation and vehicle emission policies favored diesels, amounted to a significant non-tariff trade policy, and benefited consumers provided externalities were sufficiently small. We conclude this section by asking: Did these policies violate WTO rules? The WTO considers a policy a non-tariff barrier (NTB) only if the policy is not "set at an appropriate level to achieve legitimate objectives with minimum impact on trade" (OECD, 2005) but European regulators could claim the policies did serve a legitimate objective: they benefited consumers. These results therefore highlight the difficulty of prosecuting such policies in the WTO as proving they amount to a non-tariff barrier is difficult absent a compelling piece of evidence.

\subsection{Robustness}

In this paper we find significant evidence to support the hypothesis that European fuel taxation and vehicle emissions regulation had the effect of protecting the domestic European automobile industry. Our analysis does come with caveats, however. First, the estimated model is static so we cannot account for the long-term effects of the alternative policies we considered. If we interpret the increasing valuation of diesels throughout the sample (i.e., $\hat{\beta}_{\text {DIESEL }} \times$ TREND $>0$ ) as customer learning, a small modification of the diesel fuel tax (or equivalently a small decrease in the $N O_{x}$ vehicle emission standard) early in our sample could have limited the diffusion of diesels later in the sample. Our results would then amount to a lower bound of the impact of these policies. Second, in evaluating the impact of a stricter $N O_{x}$ emission standard we account only for reductions in fuel efficiency though evidence suggest that torque is also effected by the abatement technology.

\footnotetext{
${ }^{35}$ Measuring the externality explicitly in our context is however difficult since it would require measuring changes in driving habits as a function of full prices and fuel economy.
} 
Unfortunately, our data do not include engine torque so its contribution towards the popularity of diesel vehicles can only be captured via the diesel and diesel-trend variables.

Finally, our results however depend upon the strong assumption that the set of car models (and their corresponding characteristics) would not have changed had European regulators adopted different fuel taxation and vehicle emissions standards. The goal of the analysis of this section is to convince the reader that other strategies not based on the sales of diesel automobiles would have been less profitable for the European industry. European automakers had an exclusive expertise in the production of diesel engines and the pro-diesel policies of European authorities reinforced this advantage by diverting demand away from imported fuel efficient gasoline vehicles.

There are many ways in which European firms could have responded to alternative fuel taxation and vehicle emission standards. Given the fact that consumers prefer fuel efficient vehicles $\left(\hat{\beta}_{\mathrm{KPE}}>0\right)$, we test whether European firms could have invested in redesigning their gasolinepowered vehicles to compensate for lost diesel profits due to the alternative fuel taxation and vehicle emission standards we considered above. As in our calculation of the implicit tariff, we begin from the counterfactual equilibrium where regulators chose to not adopt the pro-diesel policies and instead adopted the alternative fuel taxation and emission policies we considered. As we showed in Figure 9 such policies decrease the profits of European firms. We then unilaterally solve for the increase fuel efficiency, MPG, of European gasoline-powered cars each year required to offset the reduction of diesel profits. We also account for changes in firm costs due to changes in c90 as well as changes in vehicle prices (i.e., we resolve Equation (8) at the new vector of characteristics). It is important to note that this exercise may not generate equilibria which correspond to the Nash

Figure 11: European Firm Response

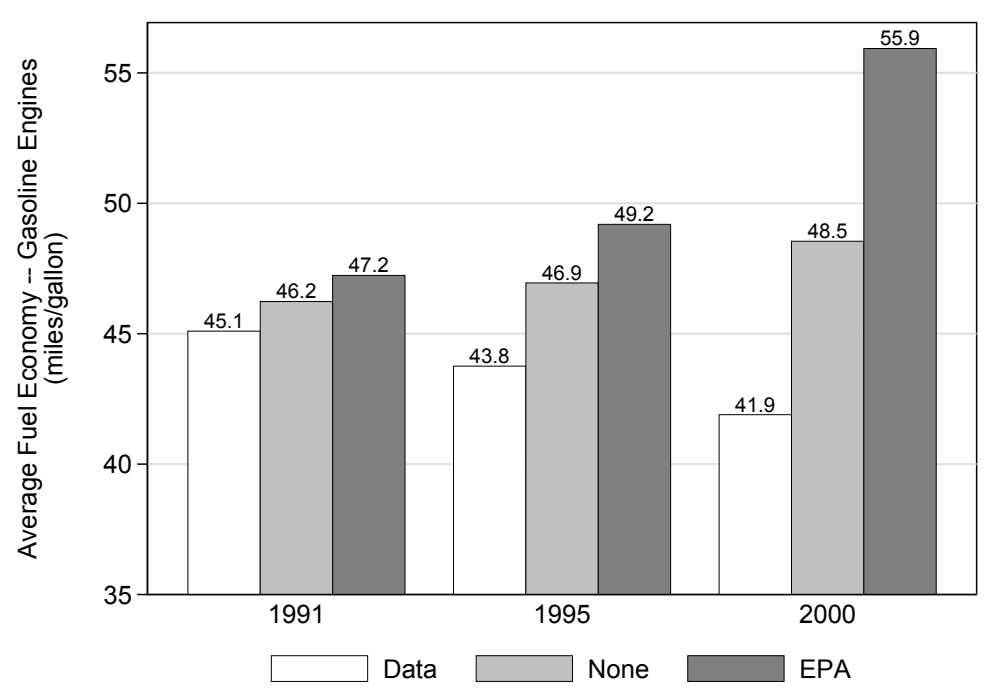

Notes: Graph depicts (sales-weighted) average gasoline fuel efficiency required for European firms to earn as much profit as estimated in the data. A similar pattern exists when comparing the simple average. In each counterfactual experiment we assume harmonized fuel taxes as described in the text. 
equilibria of a game in which firms choose characteristics, however. Instead we view this exercise as a simple way to explore whether such modifications would have been feasible.

Figure 11 reports the (sales-weighted) average mileage of the current fleet in 1991, 1995, and 2000 and compares it to the required mileage for European gasoline models that will compensate the foregone diesel profits under the "None" and the more expensive "EPA" vehicle emission scenarios. In both scenarios we assume regulators harmonize the fuel taxes charged to diesel and gasoline. For simplicity, we restrict attention to the "EPA" scenario and note that "None" amounts to an intermediate case.

At the beginning of the 1990s, when diesels generated only 13.5\% of European profits, firms could offset foregone profits from diesels by increasing the fuel efficiency of their gasoline fleet from 45.1 to 47.2 miles per gallon, a $4.7 \%$ increase. By the end of the decade - when diesels accounted for $59.3 \%$ of European firm profits - recovering the foregone profits from diesels would have required a $33.4 \%$ increase in gasoline vehicle fuel efficiency, from 41.9 to 55.9 miles per gallon. This is less than the increase in fuel efficiency expected by European authorities between 2015 and 2021, from 45 to 68 miles per gallon, respectively. It seems reasonable to assume that such levels of fuel efficiency were out of reach in the 1990s. Thus, the pro-diesel policies simply reinforced the most profitable product strategies available to European automakers.

\section{Concluding Remarks}

The goal in this paper was to estimate the tariff equivalence of two European domestic policies which favored the domestic automobile industry. To do so we estimated an equilibrium oligopoly model of differentiated products. Our estimation allowed for significant heterogeneity of preferences, finding that consumers favored fuel economy, were price-sensitive, and increased their valuations of diesel vehicles over the sample period.

We find that the pro-diesel fuel tax and vehicle emissions policies employed by the E.U. amounted to significant trade policies which we estimate to be equivalent to a $17 \%$ to $27 \%$ import tariff. This is, to the best of our knowledge, the first use of a structural equilibrium model of demand and industry oligopoly competition to show that seemingly innocuous domestic policies can be an effective replacement for traditional trade policies. Our results illustrate that in an increasingly global economy, governments can effectively construct non-trade national policies, including environmental regulations, to protect domestic industries when traditional trade policies are no longer available. We further showed that both consumers and domestic manufacturers benefited under these policies provided any health or environmental externalities are negligible. 


\section{References}

Bagwell, K. and R. W. Staiger (2001): "Domestic Policies, National Sovereignty and International Economics Institutions," Quarterly Journal of Economics, Vol. 116, pp. 519-562.

Balcer, Y. and S. A. Lippman (1984): "Technological Expectations and Adoption of Improved Technology," Journal of Economic Theory, Vol. 34, pp. 292-318.

Bergstrand, J., M. Larch, and Y. Yotov (2015): "Economic integration agreements, border effects, and distance elasticities in the gravity equation," European Economic Review, Vol. 78, pp. 307-327.

Berry, S. (1994): "Estimating Discrete-Choice Models of Product Differentiation," RAND Journal of Economics, Vol. 25, pp. 242-262.

Berry, S., J. Levinsohn, and A. Pakes (1995): "Automobile Prices in Market Equilibrium," Econometrica, Vol. 63, pp. 841-890.

(1999): "Voluntary Export Restraints on Automobiles: Evaluating Strategic Trade Policy," American Economic Review, Vol. 89, pp. 400-430.

Bhagwati, J. and V. K. Ramaswami (1963): "Domestic Distortions, Tariffs, and the Theory of Optimum Subsidy," Journal of Political Economy, Vol. 71, pp. 44-50.

Bresnahan, T. F., S. Stern, and M. Trajtenberg (1997): "Market Segmentation and the Sources of Rents from Innovation: Personal Computers in the Late 1980," RAND Journal of Economics, Vol. 28, pp. S17-S44.

Busser, R. and Y. Sadoi (2004): "Japanese Automobile Makers in Europe and the Organization of the Supply System," in R. Busser and Y. Sadoi eds. Production Networks in Asia and Europe. Skill Formation and Technology Transfer in the Automobile Industry, New York, NY: Taylor \& Francis.

Canis, B. (2012): "Why Some Fuel-Efficient Vehicles Are Not Sold Domestically," report to congress, Congressional Research Service.

Chamberlain, G. (1987): "Asymptotic Efficiency in Estimation with Conditional Moment Restrictions," Journal of Econometrics, Vol. 34, pp. 305-334.

Dagsvik, J. K. and A. Karlström (2005): "Compensating Variation and Hicksian Choice Probabilities in Random Utility Models that Are Nonlinear in Income," The Review of Economic Studies, Vol. 72, pp. 57-76.

Dubé, J.-P., J. T. Fox, and C.-L. Su (2012): "Improving the Numerical Performance of Static and Dynamic Aggregate Discrete Choice Random Coefficients Demand Estimation," Econometrica, Vol. 80, pp. 2231-2267.

Ederington, J. (2001): "International Coordination of Trade and Domestic Policies," American Economic Review, Vol. 91, pp. 1580-1593.

Feenstra, R. C. (1988): "Quality Change Under Trade Restraints in Japanese Autos," Quarterly Journal of Economics, Vol. 103, pp. 131-146.

Gandhi, A. and J.-F. Houde (2015): "Measuring Substitution Patterns in Differentiated Products Industries," Mimeo, University of Wisconsin-Madison.

Gavazza, A., A. Lizzeri, and N. Roketskiy (2014): "A Quantitative Analysis of the Used-Car Market," American Economic Review, Vol. 104, pp. 3668-3700. 
Goldberg, P. K. (1998): "Effects of the Corporate Average Fuel Efficiency Standards in the U.S.," Journal of Industrial Economics, Vol. 46, pp. 1-33.

Goldberg, P. K. and F. Verboven (2001): "The Evolution of Price Dispersion in the European Car Market," Review of Economic Studies, Vol. 68, pp. 811-848.

(2005): "Market Integration and Convergence to the Law of One Price: Evidence from the European Car Market," Journal of International Economics, Vol. 65, pp. 49-73.

Grigolon, L., M. Reynaert, and F. Verboven (2017): "Consumer Valuation of Fuel Costs and the Effectiveness of Tax Policy: Evidence from the European Car Market," American Economic Journal: Economic Policy (forthcoming).

Grigolon, L. and F. Verboven (2014): "Nested Logit or Random Coefficients Logit? A Comparison of Alternative Discrete Choice Models of Product Differentiation," Review of Economics and Statistics, Vol. 66, pp. 916-935.

Hoon Hyun, J. (2008): "A Comparative Analysis of Transplants and Industrial Location of Japanese and Korean Automotive Industries in Europe," International Journal of Business, Vol. 13, pp. 215-235.

Ito, K. and J. M. Sallee (2017): "The Economics of Attribute-Based Regulation: Theory and Evidence from Fuel-Economy Standards," The Review of Economics and Statistics, p. forthcoming.

Jacobsen, M. R. (2013): "Evaluating U.S. Fuel Economy Standards in a Model with Producer and Household Heterogeneity," American Economic Journal: Economic Policy, Vol. 5, pp. $1-26$.

Kato, M. (1997): "Japanese Automakers Struggle in Europe," working paper, NLI Research Institute.

Knittel, C. R. and K. Metaxoglou (2014): "Estimation of Random Coefficient Demand Models: Two Empiricists' Perspective," Review of Economics and Statistics, Vol. 96, pp. 34-59.

Manuelli, R. and A. Seshadri (2014): "Frictionless Technology Diffusion: The Case of Tractors," American Economic Review, Vol. 104, pp. 1368-1391.

Moral, M. J. and J. Jaumandreu (2007): "Automobile Demand, Model Cycle and Age Effects," Spanish Economic Review, Vol. 9, pp. 193-218.

Nevo, A. (2000): "Mergers with differentiated Products: The Case of the Ready-to-Eat Cereal Industry," RAND Journal of Economics, Vol. 31, pp. 395-421.

OECD (2005): "Looking Beyond Tariffs: The Role of Non-Tariff Barriers in World Trade."

Reynaert, M. and F. Verboven (2014): "Improving the Performance of Random Coeffcients Demand Models: the Role of Optimal Instruments," Journal of Econometrics, Vol. 179, pp. 83-98.

Schiraldi, P. (2011): “Automobile Replacement: a Dynamic Structural Approach," RAND Journal of Economics, Vol. 42, pp. 266-291.

Schumpeter, J. A. (1950): Capitalism, Socialism, and Democracy, New York, NY: Harper \& Row, 3rd edition.

Seidenfuss, K.-U. and Y. Kathawala (2010): "Voluntary Export Restraint (VER) without market Restraints? The Case Study of the Monitoring Agreement (1991-1999) between the Japanese Car Manufacturers and the European Union," European Business Review, Vol. 17, pp. 217-231. 
Staiger, R. W. (1995): "A Theory of Gradual Trade Liberalization," in A. V. Deardorff, J. A. Levinsohn, and R. M. Stern eds. New Directions in Trade Theory, Ann Arbor, MI: The University of Michigan Press.

Stewart, S. J. (2010): "Collection of PM Emission Data from In-Use Light-Duty Diesel and Gasoline Vehicles," Technical report, British Columbia Clean Air Research Fund Final Report, Pacific Vehicle Testing Technology, Ltd.

Sweeting, A. (2013): "Dynamic Product Positioning in Differentiated Product Markets: The Effect of Fees for Musical Performance Rights on the Commercial Radio Industry," Econometrica, Vol. 81, pp. 1763-1803.

Thurk, J. (2017): "Sincerest Form of Flattery? Business Stealing in the Imitation of Differentiated Goods," Mimeo, University of Notre Dame.

Verboven, F. (2002): "Quality-Based Price Discrimination and Tax Incidence: Evidence from Gasoline and Diesel Cars," RAND Journal of Economics, Vol. 33, pp. 275-297. 


\section{Appendix}

\section{A Data Sources}

To control for household income distribution a thousand individuals are sampled each year from the Encuesta Continua de Presupuestos Familiares (Base 1987 for years 1992-1997 and Base 1997 for years 1998-2000) conducted by INE, the Spanish Statistical Agency. ${ }^{36}$ The outside option varies significantly during the 1990s due to the important recession between 1992 and 1994 and the very fast growth of the economy and population (immigration) in the second half of the decade. We also use these consumer surveys to set the size of the outside option for each year in our sample which we compute as the total number of households minus the total number of new car registrations. Starting with 1991, the outside market share $s_{0 t}$ is: $0.93,0.92,0.94,0.93,0.93,0.93,0.92,0.91$, 0.89 , and 0.89 , respectively.

Fuel prices were also obtained from INE. We obtained Spanish steel prices, sPI, from the 2001 edition of Iron and Steel Statistics - Data 1991-2000 published by the European Commission (Table 8.1).

For the analysis of demand we build a data set using prices and vehicle characteristics as reported by La guía del comprador de coches, ed. Moredi, Madrid. We select the price and characteristics of the mid-range version of each model, i.e., the most popular and commonly sold. Demand estimation also makes use of segment dummies. Other than the LUXURY segment, which also includes sporty cars, our car segments follow the "Euro Car Segment" definition described in Section IV of "Case No. COMP/M.1406 - Hyundai/Kia." Regulation (EEC) No. 4064/89: Merger Procedure Article 6(1)(b) Decision. Brussels, 17 March 1999. CELEX Database Document No. 399M1406.

Until Spain ended its accession to the European Union transition period in 1992, it was allowed to charge import duties on European products. Similarly, import duties for non-European products converged to European levels. European imports paid tax duty of $4.4 \%$ in 1992, and nothing thereafter. Non-European manufacturers had to pay $14.4 \%$ and $10.3 \%$, respectively. Thus, for the estimation of the equilibrium random coefficient discrete choice model of Table 2 we distinguish between prices paid by consumers $(p)$ and those chosen by manufacturers $\left(p^{w}\right)$.

The other relevant factor that changes during the 1990s is the ownership structure of automobile firms. During this decade FIAT acquired ALFA ROMEO and LANCIA; FORD acquired VOLVO; and GM acquired SAAB. BMW acquired ROVER in 1994 but sold it in May 2000 (with the exception of the "Mini" brand) so these are treated as separate firms. Table A.1 describes the ownership structure at the beginning and end of the decade.

\footnotetext{
${ }^{36}$ See http://www.ine.es/jaxi/menu.do?L=1\&type=pcaxis\&path=/t25/p458\&file=inebase for a description of these databases.
} 
Table A.1: Automobile Groups: 1992 vs. 2000

\begin{tabular}{|c|c|c|c|c|c|c|}
\hline \multirow[b]{2}{*}{ Firm } & \multicolumn{3}{|c|}{ Year 1992} & \multicolumn{3}{|c|}{ Year 2000} \\
\hline & Gasoline & Diesel & Owner & Gasoline & Diesel & Owner \\
\hline ALFA ROMEO & 5,038 & 64 & ALFA ROMEO & 2,941 & 3,983 & FIAT \\
\hline AUDI & 16,689 & 1,982 & VOLKSWAGEN & 15,273 & 24,184 & VOLKSWAGEN \\
\hline BMW & 17,855 & 1,906 & BMW & 13,683 & 15,838 & BMW \\
\hline CHRYSLER & 1,243 & - & & 5,941 & 2,389 & \\
\hline CITROËN & 68,890 & 36,851 & PSA & 46,420 & 111,694 & PSA \\
\hline DAEWOO & - & - & & 25,201 & - & \\
\hline FIAT & 35,677 & 5,733 & FIAT & 30,557 & 17,967 & FIAT \\
\hline FORD & 121,140 & 17,468 & FORD & 55,268 & 57,013 & FORD \\
\hline HONDA & 4,805 & - & & 8,782 & 1,072 & \\
\hline HYUNDAI & 2,704 & - & & 30,150 & 3,590 & \\
\hline KIA & - & - & & 9,778 & 1,387 & \\
\hline LANCIA & 11,117 & 905 & LANCIA & 2,206 & 2,126 & FIAT \\
\hline MAZDA & 3,064 & - & & 2,205 & 1,480 & \\
\hline MERCEDES & 9,352 & 4,129 & MERCEDES & 13,953 & 10,684 & MERCEDES \\
\hline MITSUBISHI & 3,041 & - & & 3,660 & 1,013 & \\
\hline NISSAN & 16,010 & 905 & & 17,855 & 21,971 & \\
\hline OPEL & 110,286 & 11,099 & GM & 66,488 & 75,418 & GM \\
\hline PEUGEOT & 61,323 & 35,494 & PSA & 55,371 & 92,496 & PSA \\
\hline RENAULT & 147,907 & 27,448 & RENAULT & 76,925 & 99,360 & RENAULT \\
\hline ROVER & 15,255 & 425 & ROVER & 10,173 & 8,491 & ROVER \\
\hline SAAB & 1,551 & - & SAAB & 1,867 & 2,424 & GM \\
\hline SEAT & 85,773 & 11,787 & VOLKSWAGEN & 58,072 & 109,447 & VOLKSWAGEN \\
\hline SKODA & 724 & - & SKODA & 5,003 & 10,385 & VOLKSWAGEN \\
\hline SUZUKI & 2,058 & - & & 3,250 & 486 & \\
\hline TOYOTA & 4,425 & - & & 16,827 & 3,584 & \\
\hline VOLKSWAGEN & 50,561 & 5,471 & VOLKSWAGEN & 47,125 & 50,296 & VOLKSWAGEN \\
\hline VOLVO & 10,179 & - & VOLVO & 7,379 & 3,566 & FORD \\
\hline
\end{tabular}

Notes: Sales of vehicle by manufacturer and fuel type. "Owner" indicates the name of the automobile group with direct control on production and pricing. Those without a group are all non-European manufacturers and defined as NON-EU in the analysis.

Table A.2: Car Model Characteristics Across Segments

\begin{tabular}{lrrrrrrrr}
\hline \hline 1991 & MODELS & SHARE & PRICE & SIZE & HPW & C90 & MPG & KPE \\
\hline SMALL & 26 & 39.69 & 7.88 & 62.55 & 3.63 & 4.68 & 50.66 & 34.86 \\
COMPACT & 31 & 34.84 & 10.83 & 74.28 & 3.98 & 5.31 & 45.02 & 31.57 \\
SEDAN & 34 & 18.88 & 14.50 & 80.32 & 4.40 & 5.71 & 41.74 & 29.69 \\
LUXURY & 36 & 6.46 & 22.94 & 85.88 & 4.79 & 6.44 & 37.03 & 25.60 \\
MINIVAN & 2 & 0.13 & 20.88 & 85.16 & 3.61 & 7.11 & 33.56 & 24.12 \\
\hline ALL & 129 & 100.00 & 11.15 & 71.53 & 3.97 & 5.21 & 46.11 & 32.13 \\
\hline & & & & & & & MPG \\
\hline \hline 2000 & MODELS & SHARE & PRICE & SIZE & HPW & \multirow{2}{*}{ C90 } & \\
\hline SMALL & 49 & 32.75 & 10.42 & 66.36 & 3.18 & 4.86 & 49.11 & 31.61 \\
COMPACT & 56 & 34.43 & 14.86 & 76.54 & 3.59 & 5.00 & 48.15 & 32.53 \\
SEDAN & 52 & 25.97 & 19.45 & 81.92 & 3.63 & 5.26 & 45.72 & 31.60 \\
LUXURY & 40 & 3.72 & 34.53 & 89.72 & 5.17 & 6.72 & 36.46 & 23.31 \\
MINIVAN & 32 & 3.13 & 20.80 & 83.47 & 3.16 & 6.39 & 37.89 & 25.91 \\
\hline ALL & 229 & 100.00 & 15.52 & 75.31 & 3.51 & 5.13 & 47.07 & 31.43 \\
\hline
\end{tabular}

Notes: See definitions in Table 1. 


\section{B Japanese Automobile Sales in Europe}

In our analysis we treat all Japanese production as imported even though some models were produced in the E.U. even before the beginning of our sample. Thus, for instance, Nissan established in the U.K. in 1984 and Toyota and Honda in 1989. We argue that: (i) Most Japanese vehicles sold in the European automobile market during the 1990s were imported from Japan, (ii) Out of those produced in Europe, many were light trucks not included in our sample, and (iii) those produced in Europe could not avoid paying import tariffs because local value added was considered too low to qualify as domestic production by European rules until year 2000.

During the 1990s Japanese automakers tried to avoid E.U. import tariffs through the establishment of factories in the U.K. and later in partnership with other manufacturers in a strategy known as "Transplant Japanese Production." To avoid import tariffs, Japanese firms had to demonstrate that their models contained a sufficient amount of "local content." In France, Italy, Portugal, and Spain this amounted to $80 \%$ of value added had to be from European sources a stringent standard set at the request of European automakers. ${ }^{37}$ In the U.K. and Germany a threshold of $60 \%$ was accepted as appropriate. Seidenfuss and Kathawala (2010) document that these demanding requirements were active until 1999.

Table B.1: Japanese Models Produced in the E.U.

\begin{tabular}{lllll}
\hline \hline $\begin{array}{l}\text { Toyota* } \\
(\text { UK) }\end{array}$ & $\begin{array}{l}\text { Nissan } \\
(\text { UK })\end{array}$ & $\begin{array}{l}\text { Nissan } \\
(\text { Spain })\end{array}$ & $\begin{array}{l}\text { Honda } \\
(\text { UK })\end{array}$ & $\begin{array}{l}\text { Mitsubishi** } \\
\text { (Netherlands) }\end{array}$ \\
\hline Carina (1992-1996) & Primera (1992-2000) & Patrol (1992-2000) & Accord (1992-2000) & Carisma (1992-2000) \\
Avensis (1997-2000) & Micra (1992-2000) & $\begin{array}{l}\text { Terrano (1992-2000) } \\
\text { Civic (1994-2000) }\end{array}$ & Space Star (1998-2000) \\
Corolla (1997-2000) & Almera (1998-2000) & $\begin{array}{l}\text { Serena (1997-2000) } \\
\text { Almera (1999-2000) }\end{array}$ & & \\
& & Other Light Vehicles & \\
\hline
\end{tabular}

Notes: (*) Production in France started in 2001; (**) Mitshubishi also produced in Spain but only manufactured trucks and engines. In Netherlands Mitsubishi produced in a joint venture with Volvo. Source: Japan Automobile Manufactures Association.

Table B.1 presents car models manufactured by Toyota, Nissan, Honda, and Mitsubishi, the most important Japanese firms in Europe at the time, e.g., Kato (1997). The U.K. was the country where more Japanese passenger models were produced. Since the UK Government was less demanding in the application of the "local content" requirement, most of the production was also sold there. Before year 2000, when these models were sold in Spain, they had to face the European import tax duty rate - generally $10.3 \%$ during the sample.

In any case, the share of Japanese produced vehicles in Europe is very small. To document it we collected information on European production of those transplant factories for our sample period (1991-2000). Available data for production do not distinguish by brand and aggregate passenger cars and light trucks. Since some transplant factories operated on joint venture with

\footnotetext{
${ }^{37}$ This local content commitment by Japanese firms in the E.U. is far higher than corresponding amount in the USA, e.g., Hoon Hyun (2008).
} 
European companies, European production of Japanese vehicles is estimated as the difference between European registrations, given by ACEA, and Japanese exports to Europe, given by the Japan Automobile Manufacturers Association, JAMA. Table B.2 documents the yearly production of Japanese automobiles in Europe during the 1990s, including both passenger cars and light trucks (that we do not include in our analysis). From 1994 to 1999, the total Transplant Japanese production represented only $34 \%$ of total Japanese sales in Europe.

Table B.2: European production of Japanese Companies

\begin{tabular}{rrrrr}
\hline \hline Year & $\begin{array}{r}\text { Exports } \\
(1)\end{array}$ & $\begin{array}{r}\text { Registrations } \\
(2)\end{array}$ & $\begin{array}{r}\text { Production } \\
(2)-(1)\end{array}$ & $\begin{array}{r}\text { Production } \\
\text { on sales (\%) }\end{array}$ \\
\hline 1991 & $1,496,263$ & $1,673,575$ & 177,312 & 10.59 \\
1992 & $1,410,488$ & $1,598,169$ & 187,681 & 11.74 \\
1993 & $1,115,491$ & $1,381,085$ & 265,594 & 19.23 \\
1994 & 900,304 & $1,303,502$ & 403,198 & 30.93 \\
1995 & 782,240 & $1,287,183$ & 504,943 & 39.23 \\
1996 & 818,644 & $1,385,880$ & 567,236 & 40.93 \\
1997 & $1,081,482$ & $1,566,067$ & 484,585 & 30.94 \\
1998 & $1,192,802$ & $1,706,119$ & 513,317 & 30.09 \\
1999 & $1,182,269$ & $1,733,618$ & 551,349 & 31.80 \\
2000 & $1,004,224$ & $1,676,311$ & 672,087 & 40.09 \\
\hline
\end{tabular}

Note: Passenger cars and light vehicles are included. Source: JAMA and ACEA.

\section{EPA Cost Estimates for Abatement Diesel Vehicles}

The following information was taken from "Diesel Retrofit Devices." Environmental Protection Agency (http://www.epa.gov/cleandiesel/technologies/retrofits.htm), last updated January 23, 2013. As described in the text, the abatement technology we consider is the "Lean $N O_{x}$ Catalyst (LNC)" as this technology is most relevant for limiting $N O_{x}$ emissions in passenger cars. Our inclusion of the remaining technologies recommended by the EPA shows both the breadth of technologies available to reduce a variety of emissions as well as the variety of costs (of which the LNC is near the bottom) required to modify a vehicle.

Diesel retrofit devices for after-treatment pollution control can be installed on new or existing vehicles and equipment to reduce particulate matter $(P M)$, nitrogen oxides $\left(N O_{x}\right)$, hydrocarbons $(H C)$, or carbon monoxide $(C O)$ as well as other air pollutants. The information below provides estimated emission reductions.

Lean $N O_{x}$ Catalyst (LNC). Lean $N O_{x}$ Catalysts (LNC) use diesel fuel injected into the exhaust stream to create a catalytic reaction and reduce pollution. Verified LNCs are paired with either a DPF (Diesel Particulate Filter) or a DOC (Diesel Oxidation Catalyst). An LNC can also be paired with an active DPF to reduce $N O_{x}$ emissions and enable filter regeneration over a range of duty cycles. However, an LNC still requires specific exhaust temperatures for appropriate $N O_{x}$ emission 
Table C.1: Estimated Costs to Modify Diesel Vehicles

\begin{tabular}{lll}
\hline \hline & $\begin{array}{l}\text { Typical } N O_{x} \\
\text { Technology }\end{array}$ & \\
\hline Lean $N O_{x}$ Catalyst (LNC) & $5-40 \%$ & Typical Cost $(\$)$ \\
Selective Catalytic Reduction (SCR) & $<75 \%$ & $\$ 6,500-\$ 10,000$ \\
\hline
\end{tabular}

Source: United States Environmental Protection Agency.

control performance. LNCs can increase fuel usage by 5-7 percent (emphasis added).

Selective Catalytic Reduction (SCR). Selective Catalytic Reduction (SCR) Systems inject a reductant, also known as diesel exhaust fluid (DEF), into the exhaust stream where it reacts with a catalyst to convert $N O_{x}$ emissions to $N^{2}$ (nitrogen gas) and oxygen. The catalytic reaction requires certain temperature criteria for $N O_{x}$ reduction to occur. As with DPFs, knowing the age and type of each engine in the fleet as well as the drive cycles of the vehicles is important. Data logging must be performed to determine if the exhaust gas temperatures meet the specific SCR system requirements.

\section{Figure C.1: Selective Catalytic Reduction (SCR)}

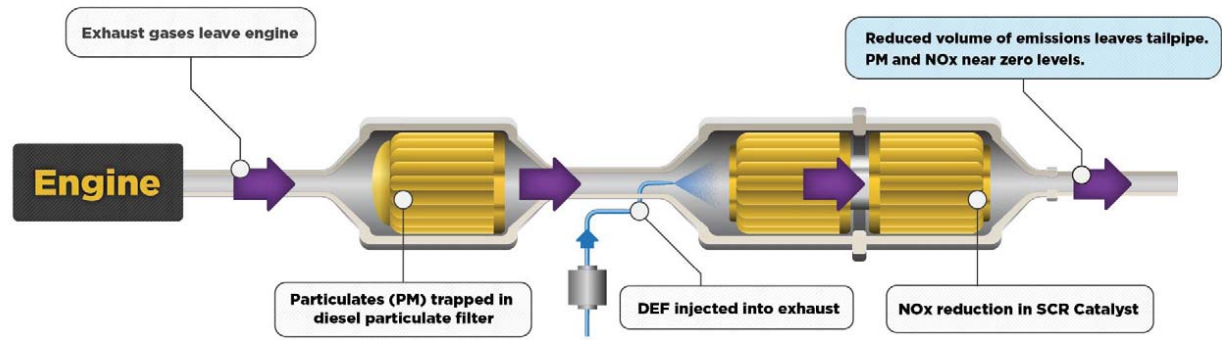

Notes: Diagram depicts the typical operation of a SCR system. The DEF sets off a chemical reaction that converts nitrogen oxide $\left(N O_{x}\right)$ into nitrogen, water and small amounts of carbon dioxide $\left(\mathrm{CO}_{2}\right)$ which are then expelled through the vehicle tailpipe. Source: www.dieselforum.org.

SCR systems require periodic refilling of the DEF by the car owner. SCR systems are commonly used in conjunction with a DOC and/or DPF to reduce $P M$ emissions. Because of new $N O_{x}$ standards, most 2010 and newer on-highway diesel engines come equipped with an SCR system. A DEF refueling infrastructure is in place, facilitating the use of SCRs. Inclusion of an SCR system adds weight to the vehicle thereby decreasing fuel efficiency (MPG) while also adding complexity to the diesel engine. 


\section{Solving for the Implicit Tariff}

In this section we provide computational details regarding solving for the import tariff equivalence of the pro-diesel fuel taxation and vehicle emission policies employed European regulators. For simplicity we describe the process to solve for the import tariff for a given year.

1. We begin by adjusting consumer demand and firm marginal costs according to the policy considered. For instance, when evaluating the joint impact of fuel taxation and vehicle emissions policy where the latter requires a $€ 3,300$ increase in marginal cost for each diesel (i.e., what we call "EPA" in the main text), we decrease fuel economy $22.5 \%$ in 2000 to capture both more expensive diesel fuel prices and the reduction in fuel efficiency due to the stricter emissions standard. We also increase the marginal cost of all diesel vehicles $€ 3,300$. We do not adjust marginal cost to reflect changes in fuel efficiency, however.

2. Solve for the pricing equilibrium by solving the system of firm FOCs represented by equation (8). Since there exists no guarantee that a unique solution satisfies this system of equations, we begin each search from a variety of different initial guesses. In practice, we found the solution to the system of FOCs was robust to the initial guess. We then record the import share at the new equilibrium prices.

3. Solve for the tariff which drives import share back down to the level observed in the data (e.g., $11.8 \%$ in 2000). This requires solving the pricing equilibrium for each potential import tariff.

We constructed the $95 \%$ confidence intervals of Figure 10 via bootstrap where we used the point estimates and standard errors for the demand and cost parameters (Table 2) to construct a random sample $(\mathrm{N}=1,000)$ of demand and cost estimates. To ease computation, we restricted the bootstrap to be over the nonlinear parameters $\{\alpha, \Sigma, \nu\}$. For each bootstrap sample $n=1, \ldots, 1000$, we begin with a set of parameters drawn from the empirical distributions defined by Table 2 . Define $\tilde{\theta}_{n}=\left\{\alpha_{n}, \Sigma_{n}, \nu_{n}\right\}$ as the bootstrap parameters for sample $n$. We recover the remaining parameters $\left\{\beta_{n}, \gamma_{n}\right\}$ following the solution method outlined in Section $5 .^{38}$ Consequently, each bootstrap simulation $n$ generates predicted market shares which match the data by construction. ${ }^{39}$

For each sample $n$ and year $t$ we solve for the import tariff equivalence of the pro-diesel fuel taxation and vehicle emission policies using the approach outlined above and the parameter vector $\left\{\alpha_{n}, \Sigma_{n}, \nu_{n}, \beta_{n}, \gamma_{n}\right\}$. The final product is a large set of implicit import tariffs which vary not only by fuel economy (KPE) and diesel marginal costs ("None" versus "EPA") but also by $\left\{\alpha_{n}, \Sigma_{n}, \nu_{n}, \beta_{n}, \gamma_{n}\right\}$. We construct the $95 \%$ confidence interval for each year as the range between the $2.5 \%$ and $97.5 \%$ quartiles, i.e., the middle $95 \%$.

\footnotetext{
${ }^{38}$ First solve for the mean utilities $\delta\left(\tilde{\theta}_{n}\right)$ such that bootstrap sample $n$ generates predicted shares equal to those observed in the data. We then recover mean utility demand $\beta\left(\tilde{\theta}_{n}\right)$ and $\operatorname{cost} \gamma\left(\tilde{\theta}_{n}\right)$ parameters via linear projection.

${ }^{39}$ One sees this fact in Figure 10, Panel (a) where the confidence interval converges to zero as $\Delta$ KPE $\downarrow 0$ (i.e., as we converge to the data equilibrium) and the implicit tariff converges to the official import tariff rate of $10.3 \%$.
} 


\section{E Additional Results}

Figure E.1: Estimated Brand Fixed Effects

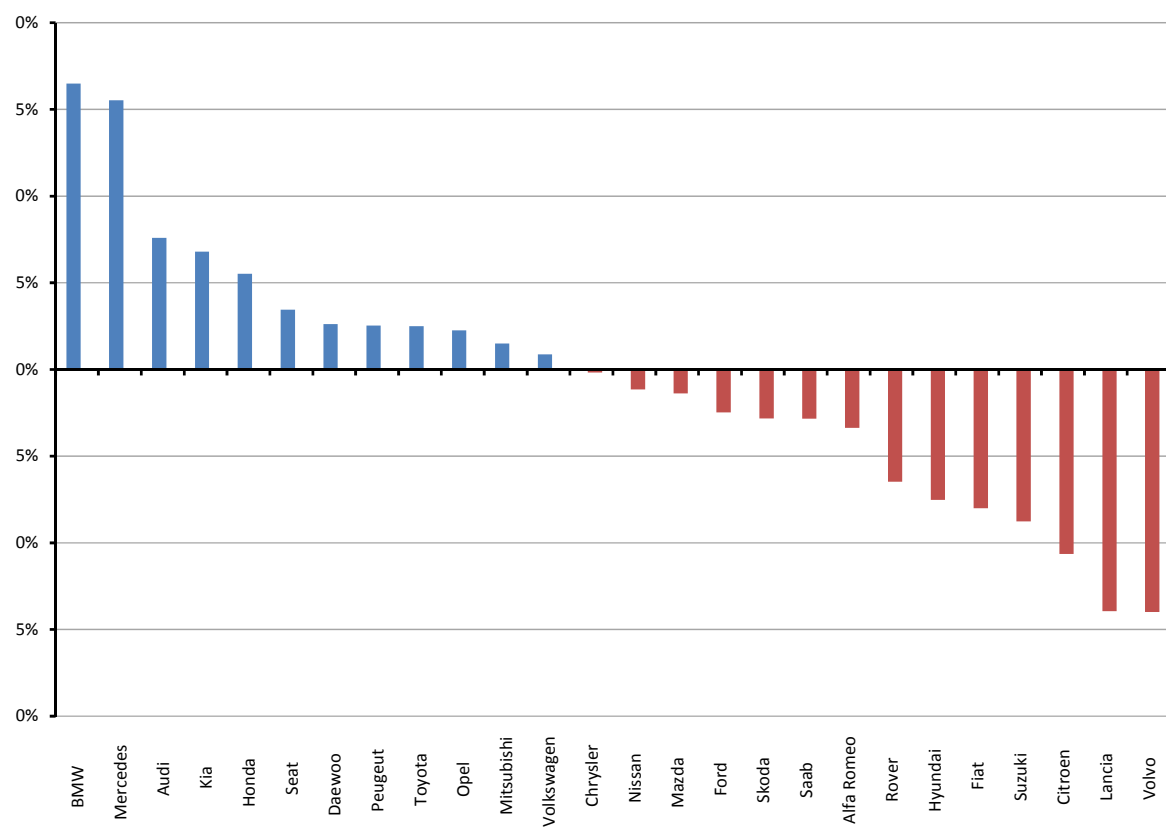

(a) Consumer Demand

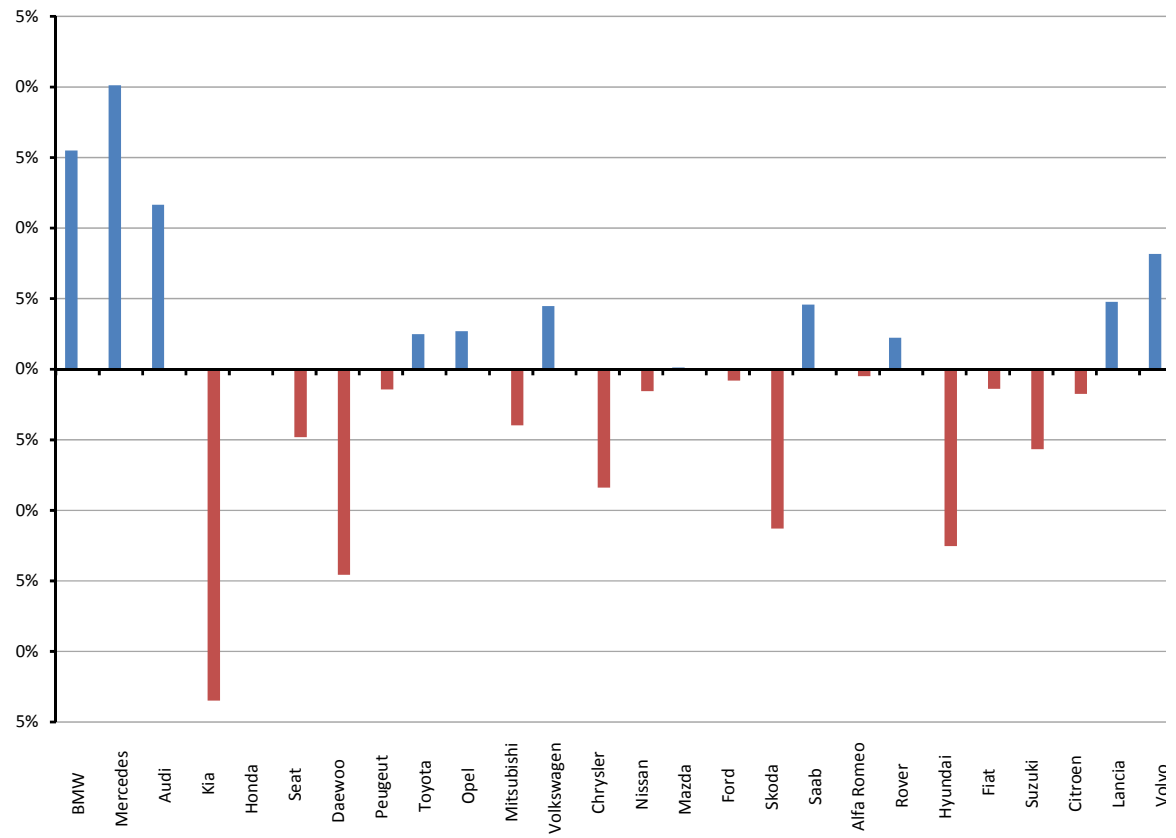

(b) Marginal Cost

Notes: Figure presents estimated brand fixed effect in demand (panel a) and production (panel b). Results are presented as percent deviations of the point estimate from the reference category, RENAULT. 


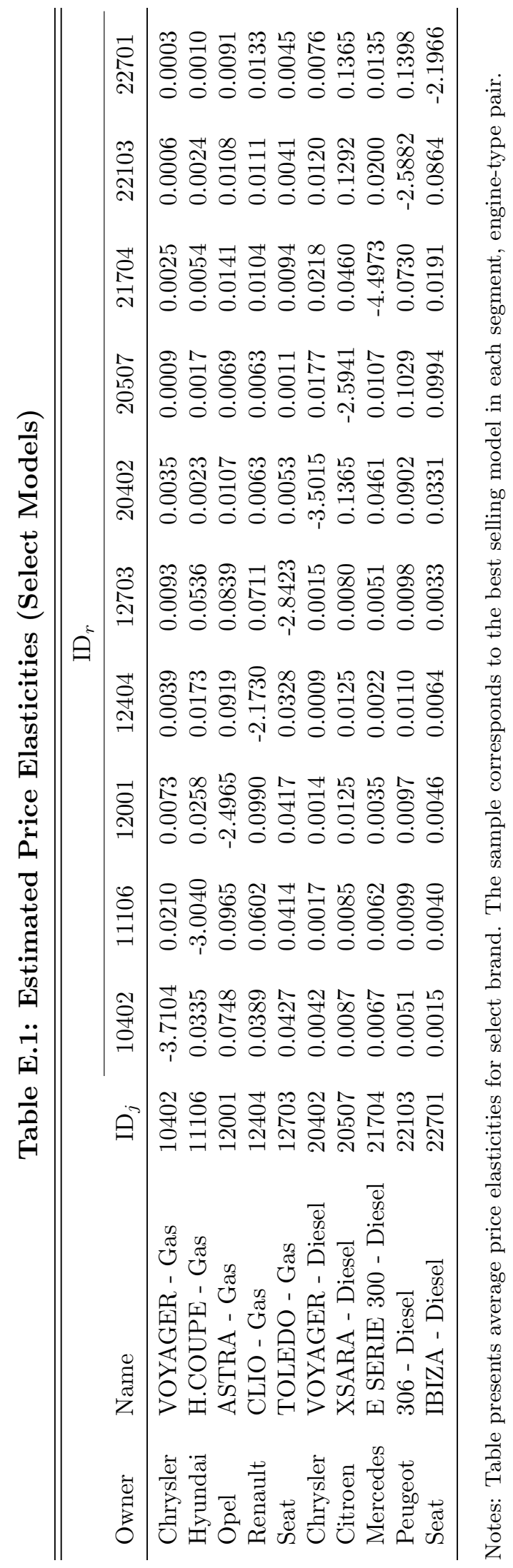


Table E.2: Estimated Best Substitutes (Select Products)

\begin{tabular}{|c|c|c|c|c|c|c|}
\hline \multirow[b]{2}{*}{ Owner } & \multirow[b]{2}{*}{ Name } & \multirow[b]{2}{*}{ Segment } & \multicolumn{4}{|c|}{ Best Substitute } \\
\hline & & & Owner & Name & Segment & Elasticity \\
\hline Ford & ESCORT - Diesel & Compact & Seat & MALAGA - Diesel & Compact & 0.2366 \\
\hline Peugeot & 306 - Diesel & Compact & Rover & SERIE 100 - Diesel & Small & 0.1810 \\
\hline Renault & MEGANE - Diesel & Compact & Hyundai & LANTRA - Diesel & Compact & 0.2194 \\
\hline Ford & ESCORT - Gas & Compact & Rover & MONTEGO - Gas & Luxury & 0.1456 \\
\hline Opel & ASTRA - Gas & Compact & Suzuki & SWIFT - Gas & Small & 0.1328 \\
\hline Renault & MEGANE - Gas & Compact & Rover & 25 - Gas & Compact & 0.1896 \\
\hline Audi & A6 - Diesel & Luxury & Opel & SINTRA - Diesel & Minivan & 0.1295 \\
\hline BMW & SERIE 5 - Diesel & Luxury & Mercedes & S Serie 4 - Diesel & Luxury & 0.2866 \\
\hline Mercedes & E SERIE 300 - Diesel & Luxury & Opel & SINTRA - Diesel & Minivan & 0.3805 \\
\hline Audi & 100 - Gas & Luxury & Renault & $25-$ Gas & Luxury & 0.0653 \\
\hline BMW & SERIE 5 - Gas & Luxury & Mercedes & S SERIE 500 - Gas & Luxury & 0.1788 \\
\hline Hyundai & H.COUPE - Gas & Luxury & Nissan & $200 \mathrm{SX}$ - Gas & Luxury & 0.0843 \\
\hline Chrysler & VOYAGER - Diesel & Minivan & Mazda & MPV - Diesel & Minivan & 0.0715 \\
\hline Opel & ZAFIRA - Diesel & Minivan & Hyundai & H-1 - Diesel & Minivan & 0.0441 \\
\hline Renault & ESPACE - Diesel & Minivan & Hyundai & H-1 - Diesel & Minivan & 0.0336 \\
\hline Chrysler & VOYAGER - Gas & Minivan & Chrysler & $300 \mathrm{M}$ - Gas & Luxury & 0.0467 \\
\hline Mercedes & SerieA - Gas & Minivan & Daewoo & TACUMA - Gas & Minivan & 0.0097 \\
\hline Opel & ZAFIRA - Gas & Minivan & Hyundai & H-1 - Gas & Minivan & 0.0399 \\
\hline Citroen & XANTIA - Diesel & Sedan & Hyundai & H-1 - Diesel & Minivan & 0.1789 \\
\hline Citroen & XSARA - Diesel & Sedan & Hyundai & H-1 - Diesel & Minivan & 0.2503 \\
\hline Seat & TOLEDO - Diesel & Sedan & Ford & FOCUS - Diesel & Compact & 0.0895 \\
\hline Ford & MONDEO - Gas & Sedan & Rover & MONTEGO - Gas & Luxury & 0.1033 \\
\hline Opel & VECTRA - Gas & Sedan & Chrysler & VISION - Gas & Luxury & 0.1018 \\
\hline Seat & TOLEDO - Gas & Sedan & VW & JETTA - Gas & Compact & 0.0909 \\
\hline Peugeot & 205 - Diesel & Small & Citroen & AX - Diesel & Small & 0.1589 \\
\hline Renault & CLIO - Diesel & Small & Seat & AROSA - Diesel & Small & 0.1200 \\
\hline Seat & IBIZA - Diesel & Small & Seat & AROSA - Diesel & Small & 0.1889 \\
\hline Opel & CORSA - Gas & Small & Seat & MARBELLA - Gas & Small & 0.1031 \\
\hline Renault & CLIO - Gas & Small & Suzuki & SWIFT - Gas & Small & 0.1582 \\
\hline Seat & IBIZA - Gas & Small & Skoda & FORMAN - Gas & Small & 0.1271 \\
\hline
\end{tabular}

Notes: Table presents the best substitute for select products. We define the best substitute as the product with the greatest average estimated cross-price elasticity. Sample of products correspond to the three most popular products in each segment, engine-type pair. Entries sorted according to segment, engine-type, and finally owner. 
Figure E.2: Which Firms Benefit from the Pro-Diesel Policies?

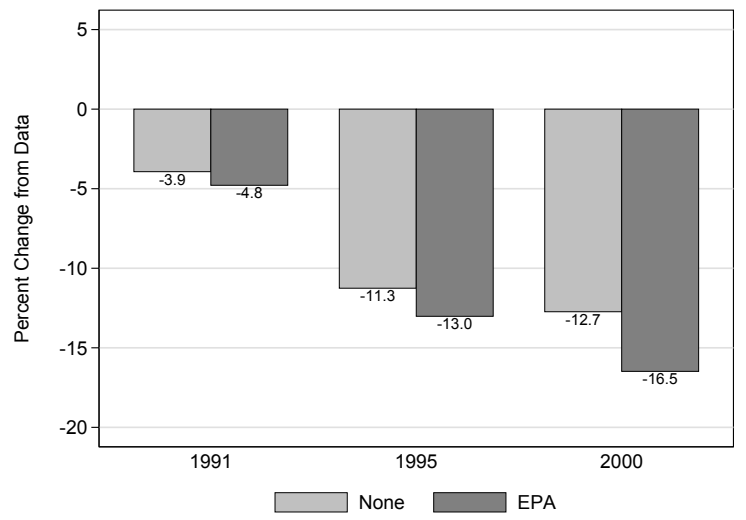

(a) European Firm Profits (Fuel Tax + Emissions)

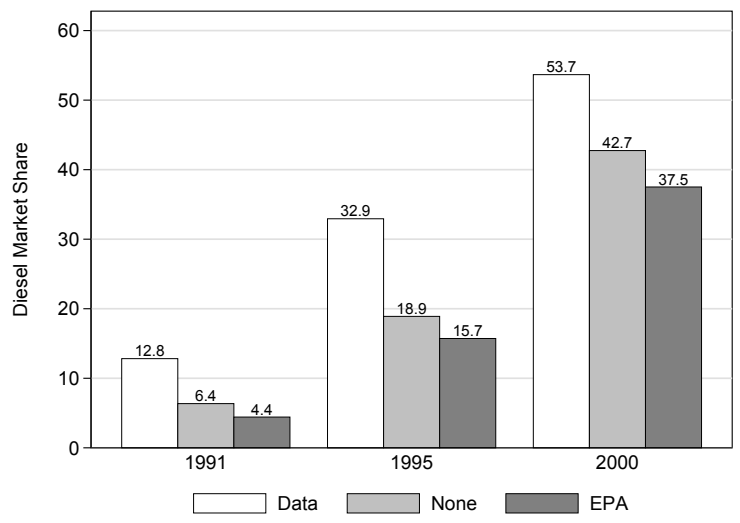

(b) Diesel Market Share (Fuel Tax + Emissions)

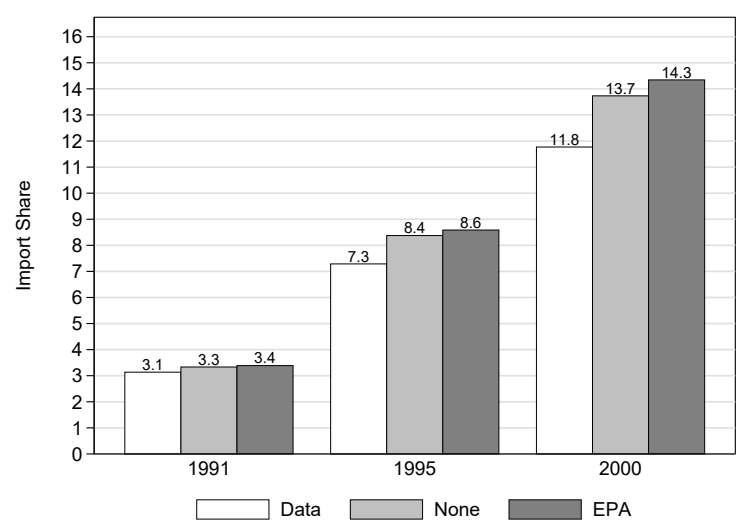

(c) Import Share (Fuel Tax + Emissions)

Notes: Panel (a) presents change in total profit for European firms when fuel taxes are harmonized and regulators impose the stricter $N O_{x}$ emissions standards. Panel (b) compares diesel market share across policies. Panel (c) presents total import share across time under the different policies. "Data" corresponds to the import share observed in the data.

Table E.3: Implicit Tariff by Year Across Policies

\begin{tabular}{|c|c|c|c|c|c|c|}
\hline \multirow[b]{2}{*}{ YEAR } & \multirow[b]{2}{*}{ DATA } & \multirow[b]{2}{*}{ FUEL TAX } & \multicolumn{2}{|c|}{ NONE } & \multicolumn{2}{|c|}{ EPA } \\
\hline & & & EMISSIONS & ВОтн & EMISSIONS & Вотн \\
\hline 1991 & 18.80 & 21.72 & 20.02 & 22.31 & 21.38 & 23.22 \\
\hline 1992 & 14.40 & 18.27 & 16.03 & 19.03 & 17.69 & 20.01 \\
\hline 1993 & 10.30 & 14.96 & 12.20 & 15.88 & 14.09 & 17.12 \\
\hline 1994 & 10.30 & 16.11 & 12.58 & 17.25 & 14.60 & 18.54 \\
\hline 1995 & 10.30 & 17.67 & 13.03 & 19.06 & 15.60 & 20.55 \\
\hline 1996 & 10.30 & 16.64 & 12.71 & 18.09 & 15.12 & 19.86 \\
\hline 1997 & 10.30 & 18.07 & 13.22 & 19.94 & 15.94 & 22.03 \\
\hline 1998 & 10.30 & 18.94 & 13.38 & 20.90 & 15.92 & 22.81 \\
\hline 1999 & 10.30 & 21.69 & 14.34 & 24.45 & 17.91 & 27.36 \\
\hline 2000 & 10.30 & 19.65 & 14.10 & 22.47 & 17.81 & 25.28 \\
\hline
\end{tabular}

Notes: "Data" is the current import tariff on foreign imports. "Fuel Tax" corresponds to the implicit import tariff for the observed fuel excise taxes (i.e., "Equalize" in the main text). "Emissions" corresponds to the implicit tariff for the observed emissions policy under the assumption that the stricter $N O_{x}$ policy requires a $€ 3,300$ increase in marginal cost ("EPA") and a $6.8 \%$ reduction in fuel efficiency for all diesels. "Both" corresponds to the implicit tariff when both policies are enforced simultaneously. 